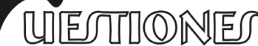 Constitucionales
}

Revista Mexicana de Derecho Constitucional

Núm. 35, julio-diciembre 2016

\section{El DERECHO A LA SALUD EN LA JURISPRUDENCIA DE LA CORTE INTERAMERICANA DE DERECHOS HUMANOS (2004-2014)}

\author{
THE RIGHT TO HEALTH IN THE CASE LAW \\ OF THE INTER-AMERICAN COURT OF HUMAN RIGHTS \\ (2004-2014)
}

Magda Yadira RoBLES*

RESUMEN: Existen factores que confluyen en la configuración y alcance del derecho humano a la protección de la salud. Uno de ellos es la posibilidad de analizar la historia de este derecho a través de la jurisprudencia establecida por nuestros tribunales nacionales e internacionales. En el caso de México, hemos presenciado desde junio de 2011 la configuración de un nuevo escenario en el que resulta relevante la necesidad de robustecer el diálogo judicial entre las instancias nacionales e internacionales, particularmente la recepción de la jurisprudencia emanada de la Corte Interamericana de Derechos Humanos. El impacto que esto tendrá en la protección del derecho a la salud plantea contextos en los que pueden construirse nuevas formas de entendimiento de este derecho. Por lo anterior, se propone en esta investigación el análisis del tejido histórico-jurídico del derecho a la salud mediante la revisión de los criterios de la Corte Interamericana de Derechos Humanos en los últimos 10 años (2004-2014). A partir de este estudio sería posible ver que la Corte ha elaborado un desarrollo jurisprudencial, por demás interesante, precisando los alcances y contenido para la protección del derecho a la salud.

Palabras clave: derechos humanos, derecho a la salud, sistema interamericano, justiciabilidad, derechos sociales.
ABSTRACT: There are factors that shaped configuration and scope of the human right to health protection. One is the possibility of analyzing the history of this law through the jurisprudence of our national and international courts. In the case of Mexico, we have witnessed since June 2011 setting a new scenario that is relevant to the need to strengthen the judicial dialogue between national and international bodies, particularly the reception of jurisprudence emanating from the Inter-American Court of Human Rights Humans. The impact this will have on the protection of the right to health posed contexts in which they can build new ways of understanding this right. Therefore, the analysis proposed in this research is the historical and legal fabric of the right to health by revising the criteria of the Inter-American Court of Human Rights over the past 10 years (2004-2014). From this study it would be possible to see that the Court has developed a jurisprudential development for other interesting specifying the scope and content to protect the right to health.

Descriptors: human rights, the right to health, inter-justiciability, social rights.

* Profesora e investigadora del Departamento de Derecho de la Universidad de Monterrey. 


\section{INTRODUCCIÓN}

El tema de la protección de los derechos sociales en los tribunales se ha vuelto un lugar central en los reclamos judiciales, en el caso del ejercicio del derecho a la salud lo vemos en su vertiente de acceso a medicamentos, accesibilidad a tratamientos médicos especializados o en su relación con otros derechos como el derecho a la vida, la vivienda, medioambiente, entre otros. Este nuevo espacio justiciable ha dado lugar a una redefinición de los derechos sociales en general, entre ellos, el derecho a la salud, como derechos exigibles derivando con ello un debate sobre su justiciabilidad.

Este debate permite ver diversas reflexiones que pueden hacerse en la configuración y alcance de la creciente intervención judicial en la protección del derecho a la salud. Éstas revelan impactos positivos de la progresión en la protección del derecho, y por otro lado, los efectos negativos que tiene la judicialización de las políticas públicas relativas a la salud.

Sin embargo, el fenómeno no es sencillo. Tomemos en cuenta que los derechos sociales en su evolución constitucional han sido diseñados como normas programáticas, siendo herederos de circunstancias tanto históricas como políticas. En el caso de México, las conquistas sociales que se plasmaron en el texto constitucional de 1917, no consistieron en deberes del Estado — salvo el derecho a la educación-, sino fundamentalmente regularon las relaciones entre particulares, de manera preponderante en los sectores campesino y obrero. Esta regulación constitucional dejó ver en poco tiempo la deficiencia - aunque similar en otras legislaciones de la épocade la regulación en materia social, destacando la falta de mecanismos para el caso de incumplimiento. ${ }^{1}$

Recientemente, hemos presenciado la configuración de un nuevo escenario: la reforma constitucional de 2011 en materia de derechos humanos, así como los efectos de la sentencia dictada por la Corte IDH en el caso Radilla Pacheco que dio lugar a la sentencia Varios 912/2010 de la Suprema Corte de Justicia de la Nación. Un hecho inédito en nuestro país porque se estableció, entre otras cosas, la obligatoriedad de las sentencias dictadas por la Corte IDH en los asuntos en que México sea parte. Otra decisión

1 Cossío Díaz, José R., "Los derechos sociales como normas programáticas y la comprensión política de la Constitución”, en Rabasa, Emilio (coord.), Ochenta años de vida constitucional en México, México, Cámara de Diputados-UNAM, Instituto de Investigaciones Jurídicas, 1998, p. 296. 
importante la vimos posteriormente en el expediente 293/2011. Esto llevó a presenciar una plataforma sobre la cual los derechos humanos deben ser analizados a la luz del derecho interno, pero también internacional, con el fin de establecer parámetros para constituir la interpretación más amplia (principio pro-persona) para la protección del derecho a la salud.

Por lo anterior, el alcance de las sentencias internacionales en materia de derechos humanos se vuelve relevante para nuestro país, porque constituirán, de acuerdo con los criterios señalados anteriormente, pautas de interpretación para los tribunales mexicanos. Para el caso que nos ocupa, nos enfocaremos en las sentencias de la Corte Interamericana de Derechos Humanos, como órgano competente para conocer de la aplicación de la Convención Americana de Derechos Humanos, conocida como Pacto de San José, la cual fue ratificada por México desde 1981.²

Sin embargo, es importante detenernos en una cuestión previa que atañe directamente con la justiciabilidad de los llamados derechos económicos, sociales y culturales en la región interamericana. Me refiero a que de acuerdo con la Convención Americana de Derechos Humanos (CADH) existen dos órganos para conocer el cumplimiento de la $\mathrm{CADH}$ : la Comisión Interamericana de los Derechos Humanos (Comisión) y la Corte Interamericana de Derechos Humanos (Corte IDH). El mismo instrumento (CADH) establece que sólo los Estados partes y la Comisión tienen competencia para someter un caso ante la Corte IDH, una vez agotados los procedimientos internos, como señala la CADH en los artículos 61 y 62.

Ahora bien, la competencia de la Corte IDH está determinada, según la misma $\mathrm{CADH}$ para conocer de cualquier caso relativo a la interpretación $\mathrm{y}$ aplicación de las disposiciones de la $\mathrm{CADH}$, siempre que los Estados partes hayan reconocido su competencia, como es el caso de México. En el caso que nos ocupa, que se refiere al derecho a la salud, su regulación se encuentra prevista, por un lado, en el artículo 26 de la CADH dentro del rubro de la progresividad de los derechos económicos, sociales y culturales. Pero por otro lado, su regulación se prevé en el Protocolo conocido como San Salvador. El cual, en el artículo 19. 6, señala que solamente los derechos establecidos en el artículo 8 párrafo a), y el artículo 13 del Protocolo,

2 México depositó el instrumento de ratificación de la Convención Americana de Derechos Humanos ante la OEA el 24 de marzo de 1981. Véase García Ramírez, Sergio y Toro Huerta, Mauricio del, México y la Corte Interamericana de Derechos Humanos. Veinticinco años de jurisprudencia, México, Instituto de Investigaciones Jurídicas, 2000, p. XVI. 
darán lugar, mediante la participación de la Comisión y cuando proceda de la Corte IDH, a la aplicación del sistema de peticiones individuales que regulan los artículos 44 a 51 y 61 a 69 de la CADH.

Esto significa, en otras palabras, que la Corte IDH sólo tiene competencia para conocer de asuntos relacionados con los derechos civiles y políticos previstos en la CADH. Fue hasta 1999, fecha de inicio de vigencia del Protocolo de San Salvador ${ }^{3}$ que el sistema interamericano ha conocido de casos, en la vía no contenciosa y contenciosa de asuntos de derechos económicos, sociales y culturales, por la Comisión y por la Corte IDH, respectivamente.

En la vía contenciosa, la Corte IDH ha podido conocer directamente los asuntos del Protocolo San Salvador cuando sean provenientes de la Comisión, y cuando se refieran a los derechos a la educación o al derecho a la sindicación. ${ }^{4}$ Sin embargo, la protección de los otros derechos económicos, sociales y culturales, como el derecho a la salud, la estrategia argumentativa de la Corte IDH ha sido el empleo de la técnica de conexidad e interdependencia e indivisibilidad de los derechos.

Es posible observar la aplicación de la técnica de los derechos por conexión en diversas sentencias del Tribunal Europeo de Derechos Humanos (TEDH), debido al limitado alcance del Convenio Europeo de Derechos Humanos en el reconocimiento de derechos sociales. Mediante esta técnica, el TEDH ha realizado una ampliación del contenido de algunos derechos civiles y políticos con prolongaciones de orden económico y social. ${ }^{5}$

En la región interamericana, este debate ha sido replanteado recientemente, en relación al caso Gonzales Lluy vs. Ecuador en las voces de los jueces que integran la Corte IDH. ${ }^{6}$ En este sentido, es posible advertir, cómo un sector de la Corte IDH ha señalado que dicho órgano judicial no tiene competencia "directa" sobre estos derechos, entre ellos, el derecho a

3 Adoptado en San Salvador el 17 de noviembre de 1998. Entró en vigor el 16 de noviembre de 1999. A la fecha, este Protocolo está vigente en 16 países: Argentina, Bolivia, Brasil, Colombia, Costa Rica, Ecuador, El Salvador, Guatemala, Honduras, México, Nicaragua, Panamá, Paraguay, Perú, Surinam y Uruguay.

4 Ventura Robles, Manuel, "Jurisprudencia de la Corte Interamericana en materia de derechos económicos, sociales y culturales”, Revista IIDH, vol. 40, 2004, p. 107.

5 Pérez Alberdi, Ma. Reyes, "La jurisprudencia social del Tribunal Europeo de Derechos Humanos", Lex Social. Revista de los Derechos Sociales, núm.1/2011, julio-diciembre de 2011, p. 94.

6 Caso Gonzales Lluy y otros vs. Ecuador, sentencia de 1 de septiembre de 2015, disponible en http://www.corteidh.or.cr/docs/casos/articulos/seriec_298_esp.pdf. 
la salud, como sí la tiene sobre los llamados derechos civiles y políticos, en general, sobre todos los derechos previstos en la CADH. Y ha dejado, a la dimensión de la progresividad de los derechos económicos, sociales y culturales como un aspecto de justiciabilidad del derecho a la salud como un derecho cuyo cumplimiento sea verificado a través únicamente del artículo 26 de la CADH y la Carta de la Organización de Estados Americanos y la Declaración Americana de los Derechos y Deberes del Hombre, como instrumentos aplicables. ${ }^{7}$

En efecto, en casos resueltos por la Corte IDH es posible advertir, al momento de interpretar derechos civiles y políticos, que ha analizado derechos sociales, como el derecho a la salud, y lo mismo en las medidas de reparación es posible ver medidas que tienen que ver con estos derechos. ${ }^{8}$ Casos paradigmáticos en este sentido lo son Comunidad Mayagna (Sumo) Awas Tingni vs. Nicaragua, Cinco pensionistas vs. Perú y lo mismo en Opiniones Consultivas. ${ }^{9}$

En contraste, el juez Ferrer Mac-Gregor en los casos Suárez Peralta vs. Ecuador ${ }^{10}$ y más recientemente en 2015, en Gonzales Lluy vs. Ecuador, ${ }^{11}$ ha impulsado una postura que afirma la posibilidad de justiciabilidad del derecho a la salud mediante la aplicación directa del artículo 26 de la CADH. ${ }^{12}$

Esta última sentencia, particularmente, es relevante para nuestro estudio porque, como lo señala el juez Ferrer Mac-Gregor, es el primer caso en la historia de la Corte IDH en el que se declara la violación de una norma prevista en el Protocolo de San Salvador. En efecto, se hace la declaración de violación del derecho a la educación, consagrado en el artículo 13 de

7 Voto concurrente del juez Humberto Antonio Sierra Porto, caso Gonzales Lluy y otros vs. Ecuador..., cit.

8 Ventura Robles, Manuel, op. cit., pp. 107 y 108.

9 Ibidem, p. 108.

10 Voto concurrente del juez Eduardo Ferrer Mac-Gregor Poisot, caso Suárez Peralta vs. Ecuador. Excepciones preliminares, fondo, reparaciones y costas, sentencia de 21 de mayo de 2013, serie C, núm. 261, disponible en http://www.corteidh.or.cr/docs/casos/ articulos/seriec_261_esp.pdf.

11 Voto concurrente del juez Eduardo Ferrer Mac-Gregor Poisot, caso Gonzales Lluy y otros vs. Ecuador. Excepciones preliminares, fondo, reparaciones y costas, sentencia de 1 de septiembre de 2015, p. 2, disponible en http://www.corteidh.or.cr/cf/Jurispruden cia2/busqueda_casos_contenciosos.cfm?lang=es.

12 Al voto del juez Eduardo Ferrer Mac-Gregor Poisot se adhirieron los jueces Roberto F. Caldas y Manuel E. Ventura Robles. 
dicho Protocolo, al tener en cuenta la situación de discriminación por motivos de salud. ${ }^{13}$

Sirve este caso para abrir el debate en torno a la posibilidad de que la Corte IDH podría directamente abordar el derecho a la salud y la eventual declaración de violación del artículo 26 de la CADH, que hemos comentado antes. Como puede observarse, el caso significa un parteaguas en el sistema de jurisprudencia de la Corte IDH en materia de derecho a la salud hasta ahora visto.

En este contexto, el análisis que se propone a continuación es la revisión de los criterios de la Corte IDH en materia del derecho a la salud en los últimos diez años. A partir de este estudio sería posible ver que la Corte IDH ha elaborado un desarrollo histórico por demás interesante precisando los alcances y contenido de dicho derecho, a través del uso de la técnica de conexión y su interdependencia con otros derechos, mediante la cual ha protegido el derecho a la salud. Finalmente, se presenta la protección del derecho a la salud en México por los tribunales. En este punto, la situación es totalmente diferente, ya que el derecho a la salud ha sido considerado por la Suprema Corte de Justicia de la Nación, como un derecho directamente justiciable. Por tanto, las conclusiones de nuestro estudio implicarían algunas consideraciones sobre la situación de la protección del derecho a la salud a nivel interno respecto de la protección brindada en el sistema interamericano. Veamos con detalle este itinerario.

\section{ELEMENTOS PARA EL ESTUDIO}

\section{La salud como derecho humano}

Como es bien sabido, la división de derechos humanos en dos grandes categorías responde básicamente a un factor diferencial que refiere a los diferentes medios de garantía. El primer grupo, el de los derechos civiles y políticos cuentan con desarrollados mecanismos de garantía en la medida que exigen la no intervención del Estado (derechos de libertad e integridad física) o bien, la realización de condiciones o mecanismos políticos (como las votaciones), los cuales exigen del Estado la disposición de mecanismos institucionales para castigar a quien los vulnere.

13 Voto particular del juez Eduardo Ferrer Mac-Gregor, cit., p. 2. 
En cambio, los derechos sociales, económicos y culturales, que aspiran a lograr el bienestar de las personas y crear las condiciones de igualdad que permitan que las personas gocen de todos los derechos, suponen más dificultades porque implica la actividad del Estado prestando dichos servicios y bienes, dada su naturaleza prestacional. En este estadio de los derechos, la mayor o menor garantía de los derechos económicos, sociales y culturales dependerá, en gran medida, de la capacidad económica de los Estados. ${ }^{14}$

En primer término, es importante precisar sobre el contenido obligacional del derecho a la salud en el ámbito interamericano. El derecho a la salud se encuentra previsto en el artículo 10 del Protocolo Adicional a la Convención Americana de Derechos Humanos de Derechos Económicos, Sociales y Culturales (en adelante, el Protocolo, o Protocolo de San Salvador) en estos términos:

1. Toda persona tiene derecho a la salud, entendida como el disfrute del más alto nivel de bienestar físico, mental y social.

2. Con el fin de hacer efectivo el derecho a la salud los Estados partes se comprometen a reconocer la salud como un bien público y particularmente a adoptar las siguientes medidas para garantizar este derecho:

a. La atención primaria de la salud, entendiendo como tal la asistencia sanitaria esencial puesta al alcance de todos los individuos y familiares de la comunidad.

b. La extensión de los beneficios de los servicios de salud a todos los individuos sujetos a la jurisdicción del Estado.

c. La total inmunización contra las principales enfermedades infecciosas.

d. La prevención y el tratamiento de las enfermedades endémicas, profesionales y de otra índole.

e. La educación de la población sobre la prevención y tratamiento de los problemas de salud, y

f. La satisfacción de las necesidades de salud de los grupos de más alto riesgo y que por sus condiciones de pobreza sean más vulnerables.

Por otra parte, la protección que otorga la $\mathrm{CADH}$ respecto a los derechos económicos, sociales y culturales se encuentra prevista en el artículo

14 Talavera, Pedro, "El derecho humano a la salud frente a las condiciones biosanitarias del planeta”, Revista Europea de Derechos Fundamentales, núm. 12, 2o. semestre, 2008, p. 100. 
26 de la citada Convención. La cual alude al deber de "progresividad" de estos derechos. En este sentido, el artículo 26 señala que es compromiso de los Estados partes adoptar las providencias tanto a nivel interno como de cooperación internacional para lograr progresivamente la plena efectividad de las normas económicas, sociales, de educación, ciencia y cultura contenidas en la Carta de la OEA. Además, añade que estas medidas serán adoptadas en la medida de los recursos disponibles, ya sea empleando los medios legislativos $\mathrm{u}$ otros apropiados al caso.

Ahora bien, la Corte IDH, como se verá más adelante, utiliza diversas interpretaciones del derecho a la salud desde la perspectiva internacional, así por ejemplo, podemos considerar al Comité de Derechos Económicos Sociales y Culturales, en la Observación General número 14, al decir que el derecho a la salud comprende: un sistema de protección de la salud que brinde a todos iguales oportunidades para disfrutar del más alto nivel posible de salud; el derecho a la prevención y el tratamiento de las enfermedades, y la lucha contra ellas; el acceso a medicamentos esenciales; la salud materna, infantil y reproductiva; el acceso igual y oportuno a los servicios de salud básicos; el acceso a la educación y la información sobre cuestiones relacionadas con la salud; la participación de la población en el proceso de adopción de decisiones en cuestiones relacionadas con la salud a nivel comunitario y nacional. ${ }^{15}$

\section{Particularidades del litigio en materia de salud (2004-2015)}

En las líneas que siguen se propone una relatoría histórica de las sentencias dictadas en los casos contenciosos por la Corte IDH de 2004 a 2015. En dichos casos, se ha litigado por la Comisión Interamericana de Derechos Humanos (Comisión) la violación de derechos civiles y políticos como el derecho a la vida, a la integridad personal, a la libertad personal y a otros derechos de garantías judiciales o acceso a la justicia. En ellos, la Corte IDH ha hecho pronunciamientos sobre el derecho a la protección de la salud, por la

15 Aplicación del Pacto Internacional de los Derechos Económicos, Sociales y Culturales, Observación general 14, "El derecho al disfrute del más alto nivel posible de salud" (artículo 12 del Pacto Internacional de Derechos Económicos, Sociales y Culturales), 22o. periodo de sesiones, 2000, UN Doc. E/C.12/2000/4, disponible en http://conf-dts1. unog.ch/1\%20SPA/Tradutek/Derechos_hum_Base/CESCR/00_1_obs_grales_Cte\%20 Dchos\%20Ec\%20Soc\%20Cult.html\#GEN14. 
vía de la interdependencia de los derechos o la conexión entre los mismos, como ya se ha señalado. Para entrar en este estudio, precisemos algunos datos sobre los asuntos llevados a juicio por la Comisión ante la Corte IDH.

Se identifican tres aspectos relevantes para el estudio de esta actividad. En primer término, seleccionamos como base de nuestro estudio veinticinco sentencias que refieren como derechos vulnerados, entre otros, el derecho a la salud. Aquí es interesante destacar que el derecho a la protección de la salud aparece interconectado con otros derechos. En doce casos las víctimas son grupos vulnerables (como niños, indígenas o migrantes). Catorce casos refieren violaciones a los derechos de personas en su calidad de detenidos o bien, por violaciones a la integridad personal como tortura y tratos crueles e inhumanos. Cuatro casos refieren específicamente a violaciones cometidas por personal de salud. Y cinco casos protegieron el derecho a la salud por su vinculación con el deber del Estado de garantizar el derecho a la vida.

Otro aspecto quizá menos relevante, pero significativo por la trayectoria en la configuración del derecho es el lapso que analizaremos en este trabajo. Como es sabido, el inicio de vigencia del Protocolo de San Salvador, en el que se prescriben los derechos económicos, sociales y culturales, entre ellos el derecho a la salud, es de 1999. Por tanto, como ha señalado el juez Manuel Ventura, será a partir de este año que la Corte IDH inicie el tratamiento y análisis de estos derechos. Así, será posible ver en este estudio sentencias dictadas entre 2004 y 2014, para considerar diez años de jurisprudencia en razón de fijar un periodo concreto de estudio. Pero se incluye también un caso interesante y punto de debate de este estudio que es el TGGL y otros vs. Ecuador dictado en 2015.

Se verá que a partir de 2004 la Corte IDH inicia a consolidar criterios relacionados con la violación a los derechos a la integridad en menores en centros penitenciarios donde la sentencia señala la obligación del Estado de brindar asistencia médica a los internos en el caso Instituto de Reeducación del Menor vs. Paraguay, ${ }^{16}$ o bien, a los derechos a la integridad personal de los migrantes en su calidad de detenidos aludiendo al derecho a la salud al condenar al Estado por no brindar la atención médica necesaria por enfermedad de las personas detenidas, como pronunció en el caso Tibi vs.

16 Caso "Instituto de Reeducación del Menor" vs. Paraguay. Excepciones preliminares, fondo, reparaciones y costas, sentencia de 2 de septiembre de 2004, serie C, núm. 112, disponible en http://www.corteidh.or.cr/docs/casos/articulos/seriec_112_esp.pdf. 
Ecuador, ${ }^{17}$ y en el caso De la Cruz Flores vs. Perú, ${ }^{18}$ la detenida falleció por las condiciones en su detención y no brindarle la oportuna atención médica en su condición de detenida.

En los años siguientes, la Corte IDH elaboró una teoría interesante en la que construye el deber de proteger la salud con la garantía de otros derechos. Entonces, podremos ver históricamente, que a partir de 2005 resolvió asuntos relacionados con personas con tortura y tratos crueles durante la detención, ${ }^{19}$ comunidades indígenas ${ }^{20}$ y personas con discapacidad. ${ }^{21}$ Durante 2006 el caso Montero Aranguren vs. Venezuela ${ }^{22}$ nos da también elementos sobre el deber de atención médica del Estado a los detenidos. $\mathrm{O}$ bien, en relación con la protección debida a grupos vulnerables como niños, mujeres embarazadas y personas adultas mayores. ${ }^{23}$ En 2007 y 2008 reiteró el criterio en relación con el deber del Estado de respetar la vida e integridad personal de las personas detenidas ${ }^{24} \mathrm{y}$ de proteger a las perso-

17 Caso Tibi vs. Ecuador. Excepciones preliminares, fondo, reparaciones y costas, sentencia de 7 de septiembre de 2004, serie C, núm. 114, disponible en http://www.cor teidh.or.cr/docs/casos/articulos/seriec_114_esp.pdf.

18 Caso De la Cruz Flores vs. Ecuador. Fondo, reparaciones y costas, sentencia de 18 de noviembre de 2004, serie C, núm. 115, disponible en http://www.corteidh.or.cr/docs/ casos/articulos/seriec_115_esp.pdf.

19 Caso Gutiérrez Soler vs. Colombia, sentencia de 12 de septiembre de 2005, serie C, núm. 132, disponible en http://www.corteidh.or.cr/docs/casos/articulos/seriec_132_esp. $p d f$.

20 Caso comunidad indígena Yakye Axa vs. Paraguay. Fondo, reparaciones y costas, sentencia de 17 de junio de 2005, serie C, núm. 125 y serie C, núm. 142, disponible en http://www.corteidh.or.cr/docs/casos/articulos/seriec_125_esp.pdf.

21 Caso Ximenes Lopes vs. Brasil. Excepción preliminar, sentencia de 30 de noviembre de 2005, serie C, núm. 139, disponible en http://www.corteidh.or.cr/docs/casos/ articulos/seriec_139_esp.pdf, y sentencia de 4 de julio de 2006, serie C, núm. 149, disponible en http://www.corteidh.or.cr/docs/casos/articulos/Seriec_149_esp.pdf; y el caso García Asto y Ramírez Rojas vs. Perú, sentencia de 25 de noviembre de 2005, serie C, núm. 137, ficha técnica disponible en http://www.corteidh.or.cr/docs/casos/articulos/se riec_137_esp.pdf.

22 Caso Montero Aranguren vs. Venezuela. Excepción preliminar, fondo, reparaciones y costas, sentencia de 5 de julio de 2006, serie C, núm. 150, disponible en http://www. corteidh.or.cr/docs/casos/articulos/seriec_150_esp.pdf.

23 Caso comunidad indigena Sawhoyamaxa vs. Paraguay. Fondo, reparaciones y costas, sentencia de 29 de marzo de 2006, serie C, núm. 146, ficha técnica disponible en http://www.corteidh.or.cr/docs/casos/articulos/seriec_146_esp2.pdf.

24 Caso Albán Cornejo y otros vs. Ecuador. Fondo, reparaciones y costas, sentencia de 22 de noviembre de 2007, serie C, núm. 171, disponible en http://www.corteidh.or.cr/ 
nas bajo su custodia. ${ }^{25}$ En 2010 la Corte IDH tuvo oportunidad de aplicar nuevamente estos criterios para pronunciarse por el deber del Estado de la asistencia médica y sanitaria, como relatan los casos de Vélez Loor vs. Panamá, ${ }^{26}$ y los casos mexicanos de Cabrera García y Montiel Flores, ${ }^{27}$ Rosendo Cantú y otra.$^{28} \mathrm{Al}$ siguiente año, se pronunció señalando el deber de brindar atención médica al presunto culpable de un delito de robo que terminó en la pérdida de la vida. ${ }^{29}$

Existe un grupo de casos relacionados con los derechos de los pueblos indígenas en los cuales la Corte IDH ha tenido oportunidad de establecer criterios de interpretación muy importantes en relación al derecho de propiedad de los pueblos y comunidades indígenas y de sus recursos naturales. Recientemente en 2012, aplicó el deber de consulta del Estado en los casos de proyectos de desarrollo que incidan en sus comunidades y afecten a su identidad cultural, como en el caso del Pueblo indígena Kichwa de Sarayaku vs. Ecuador. ${ }^{30}$

Además, este año es importante, porque en la labor de la Corte IDH destacan cuatro pronunciamientos con la protección del derecho a la salud en asuntos en los que se litigó los derechos de menores de edad con dis-

docs/casos/articulos/seriec_171_esp.pdf, y serie C, núm. 183, disponible en http://www. corteidh.or.cr/docs/casos/articulos/seriec_183_esp.pdf.

25 Caso Yvon Neptune vs. Haití, sentencia completa de 6 de mayo de 2008, serie C, núm. 180, disponible en http://www.corteidh.or.cr/docs/casos/articulos/seriec_180_ esp1.pdf.

26 Caso de Vélez Loor vs. Panamá. Excepciones preliminares, fondo, reparaciones y costas, sentencia de 23 de septiembre de 2010, serie C, núm. 218, disponible en http:// www.corteidh.or.cr/docs/casos/articulos/seriec_218_esp2.pdf.

27 Caso Cabrera García y Montiel Flores vs. México. Excepción preliminar, fondo, reparaciones y costas, sentencia de 26 de noviembre de 2010, serie $\mathrm{C}$, núm. 220, disponible en http://www.corteidh.or.cr/docs/casos/articulos/seriec_220_esp.pdf.

28 Caso Rosendo Cantú y otra vs. México. Excepción preliminar, fondo, reparaciones $y$ costas, sentencia de 31 de agosto de 2010, serie C, núm. 216, disponible en http://www. corteidh.or.cr/docs/casos/articulos/seriec_216_esp.pdf, e Interpretación de la sentencia de excepción preliminar, fondo, reparaciones y costas de 15 de mayo de 2011, serie C, núm. 225, disponible en http://corteidh.or.cr/docs/casos/articulos/seriec_225_esp.pdf.

29 Caso Vera Vera y otra vs. Ecuador. Excepción preliminar, fondo, reparaciones y costas, sentencia de 19 de mayo de 2011, serie C, núm. 226, disponible en http://www. corteidh.or.cr/docs/casos/articulos/seriec_226_esp.pdf.

30 Caso del pueblo indigena Kichwa de Sarayaku vs. Ecuador. Fondo y reparaciones, sentencia de 27 de junio de 2012, serie C, núm. 245, disponible en http://corteidh.or.cr/ docs/casos/articulos/seriec_245_esp.pdf. 
capacidad ${ }^{31}$ y el muy controvertido caso de Artavia Murillo ${ }^{32}$ en el que se determinó la infertilidad como discapacidad. También protegió a víctimas migrantes $^{33}$ y otro en el que se alegaron violaciones del derecho a la vida e integridad de los internos por falta de atención médica y hacinamiento. ${ }^{34}$

En 2013 se publicó la sentencia con responsabilidad para el Estado mexicano por casos de falta de atención médica para detenidos. ${ }^{35} \mathrm{Y}$ dos casos en los que confirma la interpretación que la afectación en la salud ${ }^{36}$ y la falta de supervisión y fiscalización del Estado en referencia a los servicios médicos suponen una vulneración al derecho a la integridad personal. ${ }^{37}$

En $2014^{38}$ se vio la conformación de una doctrina cada vez más sólida de la Corte IDH al interpretar violaciones al derecho a la integridad personal cuando las víctimas o sus familiares padecen torturas y tratos crueles e inhumanos. Cabe mencionar, como se ha apuntado, que en 2015 la sentencia dictada, en el caso Gonzales Lluy vs. Ecuador, es paradigmática en dos aspectos. Por un lado, la Corte IDH hace pronunciamiento directo de la violación al

31 Caso Furlan y familiares vs. Argentina. Excepciones preliminares, fondo, reparaciones y costas, sentencia de 31 de agosto de 2012, serie C, núm. 246, disponible en http://www.corteidh.or.cr/docs/casos/articulos/seriec_246_esp.pdf.

32 Caso Artavia Murillo y otros (fertilización in vitro) vs. Costa Rica. Excepciones preliminares, fondo, reparaciones y costas, sentencia de 28 de noviembre de 2012, serie C, núm. 257, disponible en http://www.corteidh.or.cr/docs/casos/articulos/seriec_257 esp.pdf.

33 Caso Nadege Dorzema y otros vs. República Dominicana. Fondo, reparaciones y costas, sentencia de 24 de octubre de 2012, serie C, núm. 251, disponible en http://www. corteidh.or.cr/docs/casos/articulos/seriec_251_esp.pdf.

34 Caso Pacheco Teruel y otros vs. Honduras. Fondo, reparaciones y costas, sentencia de 27 de abril de 2012, serie C, núm. 241, disponible en http://corteidh.or.cr/docs/ casos/articulos/seriec_241_esp.pdf.

35 Caso Juan García Cruz y Santiago Sánchez Silvestre, sentencia de 26 de noviembre de 2013, serie C, núm. 273, disponible en http://www.bjdh.org.mx/interamericano/ doc?ficha=187.pdf.

36 Caso familia Pacheco Tineo vs. Bolivia. Fondo, reparaciones y costas, sentencia de 25 de noviembre de 2013, serie C, núm. 272, disponible en http://www.corteidh.or.cr/ docs/casos/articulos/seriec_272_esp.pdf.

37 Caso Suárez Peralta vs. Ecuador..., cit.

38 Caso Espinoza Gonzales vs. Perú. Excepciones preliminares, fondo, reparaciones y costas, sentencia de 20 de noviembre de 2014, serie C, núm. 289, disponible en http:// www.corteidh.or.cr/docs/casos/articulos/seriec_289_esp.pdf y caso personas dominicanas y haitianas expulsadas vs. República Dominicana. Excepciones preliminares, fondo, reparaciones y costas, sentencia de 28 de agosto de 2014, serie C, núm. 282, disponible en http://www.corteidh.or.cr/docs/casos/articulos/seriec_268_esp.pdf. 
Protocolo de San Salvador, en cuanto al derecho a la educación. Y, por otro lado, la sentencia abre el debate sobre la posibilidad de que los derechos sociales, económicos y culturales sean protegidos mediante la remisión a la violación al artículo 26 de la $\mathrm{CADH}$, como se ha señalado líneas antes. Otro caso más, aún sin sentencia, es el caso Chinchilla Sandoval vs. Perú, donde una persona detenida por condena fallece en el centro penitenciario a causa de un padecimiento que no fue atendido adecuadamente. Sin duda, la sentencia ayudará en este tema en cuanto a la protección y alcances del derecho a la salud.

De aquí deriva el tercer y último aspecto a señalar. Con dieciséis años en el sistema interamericano de justicia, México ha sido condenado en siete ocasiones, de las cuales, podemos destacar cuatro de ellos en los que se hace una referencia indirecta a afectaciones al derecho a la salud. Este dato es relevante para efectos de nuestra investigación simplemente por la razón siguiente: las sentencias en las que el Estado mexicano forme parte son vinculantes para las autoridades mexicanas. Veamos este camino.

\section{La recepción en México de la jurisprudencia del sistema de justicia interamericano}

A partir de los años ochenta, México suscribe documentos importantes en materia de derechos humanos como la Convención Americana de Derechos Humanos, el Pacto Internacional de Derechos Civiles y Políticos, así como el Pacto Internacional de Derechos Económicos, Sociales y Culturales, entre otros. En efecto, la construcción de la política exterior de México en materia de reconocimiento de autoridades internacionales, en concreto con el tema de los derechos humanos, la veremos iniciar hasta 1998. Año en el cual México acepta formal y constitucionalmente la jurisdicción de la Corte IDH, junto con Haití y Brasil. ${ }^{39}$ Posteriormente, en 2002 acepta la competencia de los comités de derechos humanos de las Naciones Unidas para efectos de realizar visitas e investigaciones sobre el estado que guardan los derechos humanos en el país y encargados de la supervisión del cumplimiento de diversos tratados y las denuncias individuales por la violación a éstos.

39 García Ramírez, Sergio y Toro Huerta, Mauricio del, "México y la Corte Interamericana de Derechos Humanos. Veinticinco años de jurisprudencia”, p. XXX, disponible en http://biblio.juridicas.unam.mx/libros/6/2607/4.pdf. 
Ahora bien, resulta relevante para efectos de esta investigación hacer referencia a la recepción de la jurisprudencia emanada de las decisiones de la Corte IDH, ya que para México dicha jurisprudencia es vinculante, sea o no parte en los procesos en los que se dicte. En este sentido, cabe hacer mención que desde 2008, con motivo de Amparo en Revisión 173/2008, se señaló la necesidad de recurrir a la interpretación de este tribunal internacional para conocer su interpretación en cuanto al respeto y cumplimiento de los derechos humanos consignados en la CADH. Así veremos que los sectores de mayor recepción de la jurisprudencia internacional en nuestro país fueron en los derechos del niño y en materia electoral. ${ }^{40}$

Sin embargo, un cambio total de paradigma se dio en 2010 a raíz de la sentencia recaída en el caso Radilla Pacheco vs. México ${ }^{41}$ resuelto por la Corte IDH en 23 de noviembre de 2009. Esta histórica sentencia dio lugar al expediente Varios 912/2010 resuelto por la Suprema Corte de Justicia de la Nación el 14 de julio de 2011 y del cual se desprenden fundamentalmente los siguientes criterios.

Se estableció que la Suprema Corte no puede hacer ningún pronunciamiento que cuestione la validez de lo resuelto por la Corte IDH, ya que para el Estado mexicano dichas sentencias constituyen cosa juzgada; lo único procedente es acatar y reconocer la totalidad de la sentencia. Otro aspecto que nos interesa resaltar es que las resoluciones internacionales son obligatorias para todos los órganos del Estado mexicano, al haber figurado como parte en un litigio concreto, siendo vinculantes para el Poder Judicial no sólo los puntos de resolución concretos de la sentencia, sino la totalidad de los criterios contenidos en ella, siempre que sean más favorables a la persona, de conformidad con el artículo 1o. de la Constitución mexicana. ${ }^{42}$

Este razonamiento ha sido muy importante en el debate jurisdiccional, pues viene a constituir un nuevo paradigma en la administración de justi-

40 Carmona Tinoco, Jorge, La recepción de la jurisprudencia de la Corte Interamericana de los Derechos Humanos en el ámbito interno. El caso de México, pp. 245-290, disponible en http://www.corteidh.or.cr/tablas/r28104.pdf (consultado el 15 de agosto de 2014).

41 Caso Radilla Pacheco vs. Estados Unidos Mexicanos, sentencia dictada por la Corte Interamericana de Derechos Humanos el 23 de noviembre de 2009, disponible en http://www.corteidh.or.cr/docs/casos/articulos/seriec_209_esp.pdf(consultado el 5 de octubre de 2014).

42 Contradicción de tesis 293/2011, Pleno de la Suprema Corte de Justicia de la Nación, 3 de septiembre de 2013. Tesis P/J: 21/2014 (10a.), Gaceta del Semanario Judicial de la Federación, libro 5, t. I, abril de 2014, p. 204. 
cia, que propiciará cambios trascendentes en ésta: como la incorporación del principio pro homine y parámetros de convencionalidad, como lo es el caso de la obligatoriedad de las sentencias dictadas por la Corte IDH en los casos que México sea o no parte. ${ }^{43}$

El impacto que esto tendrá en la protección del derecho a la salud adquiere nuevas dimensiones que suponen un escenario por demás interesante. Se plantean contextos en los que pueden construirse nuevas formas de entendimiento de este derecho. Esto es, se establece por un lado criterios de interpretación sobre los alcances del derecho a la salud; y, por otro, guías que orientan sobre la relación de este derecho para la consecución de otros derechos humanos.

Precisamente, para el estudio de estos criterios de interpretación de la CADH y el Protocolo de San Salvador, es preciso puntualizar que la categorización que se usará para la revisión de los casos surge al analizar 25 casos. Se observa que los argumentos de violación esgrimidos por la Comisión se refieren, en lo general, a tres derechos civiles y políticos previstos en la $\mathrm{CADH}$ : éstos son el derecho a la vida; la integridad y libertad personales, y las garantías judiciales.

Cuando se estudió por separado cada caso, se observó también que las víctimas tenían que ver con personas en situación de detención o internamiento, hechos de tortura o tratos crueles, violaciones a la libertad personal y a las garantías mínimas en los procedimientos judiciales. Entonces, para el estudio de los casos, en estos diez años de jurisprudencia, se realiza una categorización que puede ayudarnos a analizar desde los derechos civiles y políticos de la CADH hasta su vinculación con el derecho a la salud.

En este sentido, aparecen las dos primeras categorías y su conexión con el derecho a la salud. Posteriormente, destaco otro grupo de sentencias en donde el derecho alegado refiere a las garantías judiciales y procesales en los juicios. En este caso, las sentencias hacían referencia a la protección a grupos en situación de vulnerabilidad o de discriminación histórica, como son las comunidades y pueblos indígenas, menores de edad, personas con discapacidad y migrantes. Un cuarto grupo se ubica para los casos en que la referencia a la salud se relaciona con malas prácticas médicas en hospitales privados o públicos, y el derecho social sobre los beneficios de la cultura en razón de gozar del progreso y la ciencia.

43 Cossío Díaz, José R., "Primeras implicaciones del caso Radilla", Cuestiones Constitucionales, núm. 26, junio-diciembre de 2012, p. 32. 
En este sentido, es posible que el lector repare en que varios de los casos presentados se repiten en cuanto a su contenido obligacional, pues por ejemplo, en el caso de los menores de edad, se refiere a un caso donde los derechos alegados fueron el derecho a la vida, la integridad personal y además la Corte IDH hace una mención especial porque se trataba de menores reclusos. En aras de analizar cada aspecto del derecho individual analizado por la Corte IDH y su conexión con el derecho a la salud, debo la reiteración en la mención de los casos.

\section{EXPOSICIÓN DE CASOS}

\section{Derecho a la salud, derecho a la vida y vida digna}

En este rubro se analizan sentencias emitidas por la Corte IDH que agrupan casos en los cuales la Comisión litigió la presunta responsabilidad del Estado en la violación de los derechos a la vida y a la vida digna. Este último se trata de un concepto derivado de la doctrina jurisprudencial que comprende elementos de tipo económico y social que la Corte IDH decide proteger porque su disfrute depende de la vigencia del derecho a la vida.

De conformidad con el artículo 4 de la $\mathrm{CADH}$, el cual postula que toda persona tiene derecho a que se le respete la vida, la Corte IDH ha sostenido que el derecho a la vida es un derecho humano cuyo goce pleno es un prerrequisito para el disfrute de todos los demás derechos humanos. De no ser respetado, todos los derechos carecen de sentido. En tal entendimiento, a partir de este lugar fundamental que se le asigna, los Estados, tienen la obligación de garantizar la creación de las condiciones necesarias para que no se produzcan violaciones de ese derecho inalienable, así como el deber de impedir que sus agentes, o particulares, atenten contra el mismo.

\section{Responsabilidad del Estado por la ausencia de normas} sanitarias y de atención médica

En este sentido, resulta clarificador el caso Albán Cornejo vs. Ecuador ${ }^{44}$ que se refiere a la responsabilidad internacional del Estado por falta de

44 Caso Albán Cornejo y otros vs. Ecuador..., cit. 
investigación y sanción de los responsables de la muerte de Laura Albán Cornejo en un hospital privado por negligencia médica. El análisis de fondo que realiza la Corte IDH en este caso resulta interesante porque a pesar de no contar con elementos suficientes para atribuir al Estado la responsabilidad de la muerte de Laura Albán, examina la obligación de garantizar el derecho a la vida, mediante una investigación para esclarecer la denuncia presentada por la comisión de un delito. Y, por otro lado, hace evidente la importancia del expediente médico adecuadamente integrado. En este caso, la falta de expediente, así como la ausencia de normas que regulan esta materia constituyeron omisiones que hacen patente la responsabilidad del Estado. ${ }^{45}$

\section{Respeto al derecho a una vida digna implica respeto a las condiciones de salud, alimentarias, vivienda e identidad cultural}

Al respecto, la Corte IDH ha tenido ocasión de pronunciarse en relación al derecho a contar con condiciones dignas de existencia, entre ellas, la protección de la salud. Casos que ejemplifican lo anterior son el caso de la Comunidad Indigena Yakye Axa vs. Paraguay, y el caso Instituto de Reeducación del Menor vs. Paraguay.

Las tierras del Chaco de Paraguay, habitadas por la comunidad indígena Yakye Axa — conformada por más de 300 personas —, fueron vendidas a empresarios británicos. En un principio, los miembros de la comunidad fueron contratados en las estancias ganaderas que se instalaron en estos territorios. Posteriormente, se trasladaron a otra extensión de tierra debido a las graves condiciones de vida que tenían dichas estancias. Las condiciones de vida de la comunidad no mejoraron. Por lo que en 1993 algunos miembros de esta comunidad iniciaron los trámites para reivindicar las tierras que consideraban como su hábitat original. Desde 1996 algunas familias viven en un costado de la carretera y otras se trasladaron a diversas aldeas de la zona.

En la sentencia, la Corte IDH hace señalamiento de tres grupos de derechos violentados por el Estado de Paraguay en el presente caso. Los

45 Párrafo 68 de la sentencia. En este caso, la Corte IDH consideró fundamental que existan órganos de supervisión profesional para conocer y controlar el ejercicio profesional de los médicos, guiándose por los lineamientos aceptados de la ética, bioética, la ciencia y la técnica. 
dos primeros hacen referencia a las garantías de protección judicial ${ }^{46}$ y al derecho de propiedad privada. ${ }^{47}$ Me enfocaré al tercer grupo de derechos violentados, pues la interpretación remite a las condiciones de existencia digna de las comunidades.

En efecto, la Corte IDH sostiene que el derecho a la vida comprende no sólo el derecho de todo ser humano de no ser privado de la vida arbitrariamente, sino también el derecho a que no se generen las condiciones que le impidan o dificulten el acceso a una existencia digna. ${ }^{48}$ Así, en el presente caso, la Corte IDH estableció la responsabilidad del Estado en dos aspectos: el deber general de garantía (del artículo 1.1 de la CADH) y el deber de desarrollo progresivo (artículo 26 de la CADH y los artículos 10, 11, 12, 13 y 14 del Protocolo de San Salvador).

Respecto al primer aspecto, la Corte IDH estableció que el Estado generó condiciones que dificultaron el acceso a una vida digna de los miembros de la comunidad, pues la demora inexplicable del procedimiento propició las condiciones de miseria extrema, así como la precariedad del asentamiento temporal en el que se vieron obligados a permanecer a la espera de respuesta a la solicitud de reivindicación de sus tierras.

Por otro lado, la Corte IDH estimó que el Estado no cumplió con el deber de adoptar las medidas positivas apropiadas para satisfacer el derecho a una vida digna en cuanto a las afectaciones que sufrieron en el derecho a

46 Caso comunidad indígena Yakye Axa vs. Paraguay..., cit. La Corte IDH señaló que el Estado violentó los derechos a las garantías judiciales y protección judicial efectiva en virtud de que existió una demora desproporcionada en el procedimiento reivindicatorio de las tierras indígenas que inició la comunidad. El decreto que reconoce la personería jurídica de la comunidad fue emitido tres años después de iniciado. Y por otro lado, más de 11 años en resolver el proceso administrativo de reivindicación de tierras. El cual, a la fecha de la presentación de la demanda ante la Comisión, no tenía respuesta. Adicionalmente, la Corte cita el Convenio 169 de la OIT que dispone a cargo del Estado el establecimiento de procedimientos adecuados para solucionar reivindicaciones de tierras formuladas por los pueblos interesados. Véase al respecto, los párrafos $82,85,95,98,102$ y 104 de la sentencia.

47 De acuerdo con el artículo 21 de la Convención, la Corte IDH resalta la estrecha relación que los indígenas mantienen con la tierra que habitan, la cual debe ser reconocida y comprendida como la base fundamental de su cultura, vida espiritual, supervivencia económica y su preservación y transmisión a las generaciones futuras. Por lo que al desconocerse el derecho ancestral de los miembros de estas comunidades sobre sus territorios se estaría afectando otros derechos básicos como la identidad cultural y la supervivencia misma de estas comunidades. Véanse párrafos 131 y 147 de la sentencia.

48 Párrafo 161 de la sentencia. 
la salud, el derecho a la alimentación y el acceso a agua limpia, las cuales aquejaron directamente con su derecho a tener las condiciones básicas para el ejercicio de otros derechos humanos como el derecho a la educación o el derecho a la identidad cultural. ${ }^{49}$ En particular, los ancianos deben tener protegida su salud en caso de enfermedades crónicas y en fase terminal. Se hace señalamiento del papel esencial que tienen en sus comunidades para la preservación de sus tradiciones y cultura. De tal manera, que si no se protege a los ancianos de estas comunidades, estaría siendo nugatorio el derecho a la preservación de la cultura e identidad de dichas comunidades. ${ }^{50}$

Similar criterio aplica la Corte IDH en el caso Comunidad indígena Xákmok Kásek vs. Paraguay. ${ }^{51}$ En este tenor, la Corte IDH concluyó que la falta de sus tierras ha tenido afectación en la identidad cultural de los miembros de la comunidad: sus lenguas, la pesca, la caza, la recolección fue imposible y llevó a la comunidad a disgregarse, salir de sus tierras, y perder así su identidad cultural". ${ }^{52}$

Entonces, para determinar la responsabilidad internacional del Estado, la Corte IDH revisó si se protegió el derecho a una vida digna de la comunidad a partir de estos elementos: acceso y calidad del agua, alimentación, salud y educación, así como el fallecimiento de los miembros de dicha comunidad indígena.

Resulta por demás interesante el recurso a otras fuentes que hace la Corte IDH para establecer el acceso y calidad del agua que recibieron los miembros de la comunidad. Precisamente, acudió a estándares internacionales para fijar la cantidad de litros por persona que se requieren por día para satisfacer las necesidades básicas, que incluye alimentación e higiene. Esto además de la calidad de la misma a fin de no poner en riesgos y enfermedades a la población. ${ }^{53}$ Lo mismo para el caso de la alimentación que debió el Estado

49 Párrafo 167 de la sentencia.

50 En este caso, la Corte también consideró la valía de las personas de mayor edad porque la transmisión oral de su cultura y tradiciones a las nuevas generaciones está a cargo de ellos principalmente. Párrafos 172 y 175 de la sentencia.

51 Comunidad conformada por 66 familias, cuyas tierras fueron vendidas por el Estado a finales del siglo XIX a propietarios privados que establecieron estancias, lo que obligó a la aldea Kákmok Kásek a concentrarse en los alrededores de las ahora estancias privadas, restringiendo el desarrollo de la vida comunitaria y de sus tradiciones. Ante esta situación, a partir de 1990 la comunidad vivió un largo camino judicial por recuperar sus tierras, el cual a la fecha de la sentencia de la Corte seguía sin definición.

52 Párrafo 182 de la sentencia.

53 De la evidencia presentada por el Estado de Paraguay, la Corte IDH observó que 
proveer a los miembros de la comunidad, las cuales deben ser suficientes para satisfacer las necesidades básicas diarias de alimentación por persona. ${ }^{54}$

En lo que toca al tema de la salud, la Corte IDH sostuvo que Paraguay es responsable por la falta de accesibilidad física y geográfica de establecimientos de salud para los miembros de la comunidad. Además de la omisión de medidas educativas en la materia de salud que sean respetuosas de los usos y costumbres tradicionales. Sin duda, la situación de los miembros de la comunidad estuvo fuertemente vinculada con la falta de sus tierras, ya que al no contar con sus medios de subsistencia tradicionales tuvieron que depender de las acciones estatales, lo que trajo consigo una situación de miseria extrema. ${ }^{55}$ Hace hincapié en que la falta de alimentación adecuada ha afectado el desarrollo y crecimiento de los niños, y es causa de los altos índices de atrofia y desnutrición, además de no haber recibido las vacunas según los estándares internacionales. ${ }^{56}$

En relación con el derecho a la vida, la Corte IDH relacionó su cumplimiento con el derecho a la consulta, sobre el cual ha fijado precedentes en casos específicos. En 2012 se pronunció directamente sobre el ejercicio de este derecho en el caso pueblo indigena Kichwa de Sarayaku vs. Ecuador. ${ }^{57}$ Pueblo indígena que fue privado de sus tierras por una concesión petrolera

de mayo a agosto de 2009 la cantidad suministrada no superó los 2.17 litros por persona al día. Tampoco demostró información actualizada del suministro de agua durante 2010. Véase párrafos 195 y 196 de la sentencia.

54 En este caso, la Corte IDH acudió a los estándares internacionales sobre la cantidad de alimento para cubrir las necesidades de alimentación por día de una persona. Aquí, la Corte IDH apunta que el Estado proporcionó aproximadamente a $0.29 \mathrm{~kg}$ de alimentos por persona por día, de acuerdo con los censos aportados. Por lo que se estimó insuficiente esta cantidad. Véase párrafo 200 de la sentencia.

55 La Corte IDH declaró en este punto la falta de prestaciones básicas para proteger el derecho a una vida digna en esta particular situación de riesgo. Para fortalecer este punto, la Corte utilizó como apoyo lo establecido por el Comité de los Derechos Económicos, Sociales y Culturales de las Naciones Unidas respecto a la pobreza. Entendida ésta como la situación extrema que limita la capacidad de un grupo de personas de ejercer el derecho a participar en todos los ámbitos de la vida cultural, y de tener acceso y contribuir a ellos en circunstancias de igualdad, afectando seriamente su esperanza en el porvenir y el disfrute de su propia cultura. Véase párrafo 216 de la sentencia.

56 Párrafos 259 y 260 de la sentencia. La Corte determinó que 11 de los 13 miembros de la comunidad, cuya muerte es imputable al Estado, eran niños o niñas. Y estableció que las causas de dichos fallecimientos se hubieran podido prevenir con una adecuada atención médica o de asistencia por parte del Estado.

57 Caso del pueblo indigena Kichwa de Sarayaku vs. Ecuador..., cit., párrafo 159. 
que destruyó reservas naturales y el medioambiente que eran sustento alimentario de la tribu. Tal como lo había establecido en procesos anteriores, la Corte IDH aplicó el criterio de que el reconocimiento del derecho a ser consultados está cimentado en el respeto al derecho a la cultura propia o identidad cultural, los cuales deben ser garantizados. ${ }^{58}$ Pues el incumplimiento de este derecho conlleva impactos significativos sobre los derechos a establecer sus propias prioridades para el desarrollo como parte de su derecho a la libre determinación, el derecho a la salud y a un medio ambiente sano, el derecho a la cultura y a la religión y los derechos de los pueblos indígenas sobre sus tierras y recursos naturales de acuerdo a sus usos y costumbres.

\section{Respeto al derecho a la vida en menores supone obligación del Estado de cuidar las condiciones de salud, alimentación e higiene en los centros penitenciarios}

Reparemos en el caso Instituto de Reeducación del Menor vs. Paraguay, ${ }^{59}$ el cual se refiere a la responsabilidad internacional del Estado por la muerte y lesiones de niños internos, así como a las deficientes condiciones de vida en dicho centro como el hacinamiento, las condiciones de las celdas, falta de alimentación y asistencia médica, psicológica y dental adecuada para su edad. La situación se complicó debido a tres incendios que ocurrieron en el Centro de 2000 al 2001, provocando lesiones en los internos y muerte en otros. Posterior al último incendio, se cerró el Centro y se iniciaron procedimientos civiles para la indemnización por daños y perjuicios y un procedimiento penal, los que nunca concluyeron.

En este asunto, tratándose de menores de edad privados de la libertad, la Corte IDH puntualizó el derecho a contar con las condiciones mínimas compatibles con la dignidad humana, mientras permanecen en el centro de detención. Adicionalmente, se hace referencia a los artículos 6 y 7 de la Convención sobre los Derechos de los Niños, los cuales incluyen el deber del Estado de garantizar en la máxima medida posible la supervivencia y desa-

\footnotetext{
58 Idem.

59 Caso del Instituto de Reeducación del Menor vs. Paraguay. Excepciones preliminares, fondo, reparaciones y costas, 2 de septiembre de 2004, serie C, núm. 112, disponible en http://www.corteidh.or.cr/docs/casos/articulos/seriec_112_esp.pdf.
} 
rrollo del niño. Si se entiende que el Estado los tiene bajo su custodia, tiene, por tanto, la obligación de proveerlos en asistencia de salud y educación. ${ }^{60}$

En esta sentencia resulta relevante el señalamiento que hace la Corte IDH respecto a la responsabilidad del Estado como resultado de la falta de atención de salud adecuada y la supervisión médica regular; incluso, algunos internos fueron trasladados a centros penitenciarios de adultos compartiendo espacio físico con ellos. Según el entender de la Corte IDH, esta situación expuso a los niños a un entorno altamente perjudicial para su desarrollo físico y mental, haciéndolos vulnerables ante terceros. Por otro lado, las condiciones del Centro posibilitaron que se produjeran tres incendios, que llevó a la muerte a varios de los niños internos de manera traumática y dolorosa, y los sobrevivientes experimentaron sufrimiento moral y físico con secuelas corporales y psicológicas, todo ello ocurrió bajo la custodia y protección del Estado. ${ }^{61}$

En síntesis, de los anteriores casos presentados es posible advertir que la Corte IDH consideró violentados los derechos a la vida al atribuir al Estado la responsabilidad por la omisión de su deber de vigilar y resguardar a las personas bajo su protección. En este caso, las condiciones de vida de los menores recluidos en centros penitenciarios, la falta de derecho de consulta de las comunidades indígenas sobre su derecho de propiedad y la debida diligencia en la práctica médica determinaron la violación al derecho a la vida. En este sentido, como la falta es irreparable, la Corte IDH en las medidas de reparación incluyó indemnización económica y además la obligación de adoptar las medidas necesarias (en el caso de las comunidades indígenas) para hacer efectivo el derecho a su identidad cultural y contar con condiciones de vida digna en cuanto a alimentación, salud, vivienda y propiedad.

\section{Derecho a la protección de la salud y derecho} a la integridad personal

Bajo este rubro se examina la correspondencia entre el derecho a la salud y los derechos a la integridad y a la libertad personal, ambos fijados en

60 La sentencia refiere a la aplicación de las Reglas Mínimas de las Naciones Unidas para la Administración de Justicia de Menores, conocidas como "Reglas de Beijing", en cuanto disponen que los menores confinados en establecimientos penitenciarios recibirán los cuidados, la protección y toda la asistencia necesaria, ya sea social, educativa, profesional, médica y física que requieran debido a su edad, sexo, personalidad y para su sano desarrollo. Párrafo 161 de la sentencia.

61 Párrafos 179 y 188 de la sentencia. 
los artículos 5 y 7 de la Convención respectivamente. Por derecho a la integridad personal, la CADH señala que:

1. Toda persona tiene derecho a que se respete su integridad física, psíquica y moral. 2. Nadie debe ser sometido a torturas ni a penas o tratos crueles, inhumanos o degradantes. Toda persona privada de libertad será tratada con el respeto debido a la dignidad inherente al ser humano. 3. La pena no puede trascender de la persona del delincuente. 4. Los procesados deben estar separados de los condenados, salvo en circunstancias excepcionales, y serán sometidos a un tratamiento adecuado a su condición de personas no condenadas.

Respecto a los menores, puntualiza que deben ser separados de los adultos y llevados ante tribunales especializados, con la mayor celeridad posible, para su tratamiento.

Un aspecto directamente vinculado con el anterior es el derecho a la libertad personal, ya que el artículo 7 de la CADH señala que toda persona tiene derecho a la libertad y la seguridad personales. Con la prohibición de privación de libertad física, salvo las condiciones fijadas por la Constitución o leyes dictadas conforme a ellas. Esto supone prohibición de detención o encarcelamiento arbitrario. Debe conocer las razones de su detención y ser notificada sin demora de los cargos formulados en su contra. Es importante este grupo de casos, porque los derechos de la CADH en este rubro señalan los derechos de los detenidos como el derecho a ser puesto a disposición de un juez y ser juzgada dentro de un plazo razonable.

En este contexto de detenciones y de tratos crueles e inhumanos que puedan sufrir con motivo de la detención, se analiza como la jurisprudencia de la Corte IDH hace referencia a violaciones al derecho a la salud enlazado con el litigio de los derechos de los reclusos y detenidos, así como reclamaciones por actos de tortura y tratos crueles e inhumanos. Aquí unos ejemplos.

\section{Obligación del Estado de preservar la salud de los detenidos en las cárceles y detención temporal}

Los hechos del caso Yvon Neptune vs. Haití concierne al tema de la privación ilegal de la libertad del señor Neptune y las condiciones de su detención en la cárcel de Haití. ${ }^{62}$ La sentencia se detiene a razonar sobre

62 Caso 12.514 ante la Corte Interamericana de Derechos Humanos. Fondo, reparaciones y costas, sentencia 6 de mayo de 2008, serie C, núm. 180. 
las condiciones de detención que vivió el señor Neptune durante la misma, en particular en la penitenciaría nacional y determina que constituyeron un tratamiento inhumano por no haber cumplido con "los requisitos materiales mínimos de un tratamiento digno". ${ }^{63}$ En este sentido, amplía diciendo que las "condiciones antihigiénicas e insalubres de la celda, así como la falta de acceso a instalaciones sanitarias adecuadas y las restricciones de movimiento por temor a sufrir agresiones físicas" a su persona, constituyen un todo incompatible con las condiciones dignas de detención que el Estado debe asegurar. ${ }^{64}$

Por otra parte, en el caso Montero Anguren vs. Venezuela ${ }^{65}$ nuevamente encontraremos la doctrina de la Corte IDH atinente al derecho a la integridad personal, con el deber del Estado de respetar los derechos de las personas. ${ }^{66}$ Aquí la Corte IDH refiere a la protección de la salud en tres aspectos: el hacinamiento, los servicios sanitarios e higiene y la atención médica debidos a las personas ahí recluidas. ${ }^{67}$ En lo que respecta a los servicios sanitarios y de higiene, la Corte IDH estimó que las indebidas condiciones de luz y ventilación, así como sanitarias pueden causar sufrimientos "de una intensidad que exceda el límite inevitable de sufrimiento que acarrea la detención [que] conllevan sentimientos de humillación [que] constituyen un desprecio a la dignidad humana [y un] severo riesgo para la salud y la vida". ${ }^{68}$

Especial atención merece el señalamiento de la Corte IDH cuando dice que el Estado debe permitir y facilitar que los detenidos sean atendidos por un médico elegido por ellos mismos o por quien ejerce su representación legal. Porque la elección de un médico que no tenga vínculos con las autoridades penitenciarias o durante la detención se convierte en una medida

63 Párrafo 138 de la sentencia.

64 El artículo 5.4 de la CADH establece que "salvo circunstancias excepcionales" los procesados deben estar separados de los condenados y ser sometidos a un tratamiento adecuado a su condición de personas no condenadas. La Corte sostuvo su criterio en el sentido de que dicha Convención impone a los estados la obligación de establecer un sistema de clasificación de los reclusos en los centros penitenciarios que garantice su internamiento en condiciones dignas y tendientes a asegurar su integridad física. Véase párrafos 139-146 de la sentencia.

65 Caso Montero Anguren vs. Venezuela. Excepción preliminar, fondo, reparaciones y costas, sentencia de 5 de julio de 2006, serie C, núm. 150.

66 Ibidem, párrafos 85 y ss. de la sentencia.

67 Ibidem, párrafo 94 de la sentencia.

68 Ibidem, párrafos 97 y 99 de la sentencia. 
de salvaguardia en contra de los malos tratos, tortura o violencia física o mental de los detenidos o reclusos. ${ }^{69}$

Otro criterio fue aplicado en el caso De la Cruz Flores vs. Ecuador ${ }^{70}$ por la detención en marzo de 1996 de la médica de profesión. Su derecho fue violentado porque penalizó la conducta de la médica, siendo que es totalmente lícito y un deber de la profesión prestar el secreto profesional, ${ }^{71}$ y porque impuso a esta médica la obligación de denunciar posibles conductas delictivas de sus pacientes con la información obtenida por el ejercicio de su profesión, ${ }^{72}$ pues consideró que los médicos tienen un derecho y un deber de guardar confidencialidad sobre la información que obtengan en su condición de médicos. ${ }^{73}$

En la sentencia tropezaremos con la ya reiterada doctrina que establece que toda persona privada de su libertad tiene derecho a vivir en una situación de detención compatible con la dignidad humana. En este caso, la evidencia permitió concluir a la Corte IDH que la señora De la Cruz fue sometida a tratos crueles, inhumanos y degradantes, y estuvo en situaciones insalubres. Adicionalmente, se probó que la señora De la Cruz sufrió de padecimientos físicos durante la detención y no recibió la atención médica adecuada. ${ }^{74}$

69 La Corte IDH sostuvo en el caso Montero Anguren vs. Venezuela..., cit., que la falta de atención médica adecuada podría considerarse en sí misma violatoria de la Convención, según las circunstancias concretas de la persona, por el tipo de padecimiento, el lapso transcurrido sin atención y sus efectos. Véase párrafo 103 de la sentencia.

70 Caso De la Cruz Flores vs. Ecuador..., cit.

71 Aquí la Corte sigue la definición de acto médico del artículo 12 del Código de Ética y Deontología del Colegio Médico del Perú que dice: “acto médico es toda acción o disposición que realiza el médico en el ejercicio de la profesión médica. Entendidos como tal, los actos de diagnóstico, terapéutica y pronóstico que realiza el médico en la atención integral de pacientes, así como los que se deriven directamente de éstos. Los actos médicos mencionados son de exclusivo ejercicio del profesional médico". Véase párrafo 94 de la sentencia.

72 Aquí resulta interesante el criterio aplicado por la Corte, cuando recuerda que el artículo 18 de la Convención de Ginebra establece que nadie puede ser "molestado o condenado por el hecho de haber prestado asistencia a heridos o enfermos". Similar a lo dispuesto en los artículos 16 del Protocolo I y artículo 10 del Protocolo II de los convenios de Ginebra, que disponen que "no se castigará a nadie por haber ejercido una actividad médica conforme a la deontología, cualesquiera hubieran sido las circunstancias o los beneficiarios de dicha actividad". Véase el párrafo 95 de la sentencia.

73 Esto lo respalda con el Código Internacional de Ética Médica de la Asociación Médica Mundial que dispone "que el médico debe guardar absoluto secreto de todo lo que se le haya confiado, incluso después de la muerte del paciente".

74 En materia de reparaciones, interesa en este caso resaltar que la Corte condenó a 
Aplica también el caso comentado anteriormente del Instituto de Reeducación del Menor que trataba de niños internos. ${ }^{75}$ Éste es por demás interesante para el estudio de los derechos sociales, especialmente, el derecho a la salud, porque la Corte IDH se pronuncia sobre la falta de atención médica adecuada y la falta de supervisión médica regular. Los incendios ocurridos llevaron a la muerte a varios de los niños internos, los heridos experimentaron sufrimiento moral y físico, y con secuelas corporales y/o psicológicas. Esta circunstancia es a todas luces violatoria del derecho a la vida y a la integridad personal de los menores, además de que no tuvieron la atención a la salud necesarias a causa de dichos siniestros. La Corte IDH consideró que los familiares de los menores internos son víctimas también de estas violaciones, como es el caso de padres y hermanos.

En la misma temática, el caso Pacheco Teruel refiere a la queja presentada por los representantes de 107 internos del Centro Penal de San Pedro Sula y sus familiares por la muerte de los internos a raíz de un incendio. ${ }^{76}$ Además, se advierte de las condiciones de hacinamiento y sobrepoblación en las que vivían sin atención médica y alimentación deficiente. En 2004 ocurrió el incendio, y el Centro carecía de los mecanismos adecuados para hacer frente a este tipo de accidentes, por lo que los internos no pudieron salir de la celda por una hora provocando muerte por asfixia y quemaduras graves. Al igual que en el anterior caso, la Corte IDH falló contra el Estado responsable porque las condiciones de detención de la celda 19 eran contrarias a la dignidad humana, el servicio de agua era inadecuado, alimentación insuficiente, sin atención médica ni acceso a visitas ni programas de rehabilitación o recreo. ${ }^{77}$

proporcionar atención médica y psicológica a la víctima mediante los servicios estatales, incluyendo la provisión gratuita de medicinas. Derivado del tiempo que estuvo detenida indebidamente, condena a pagar a la víctima una beca que le ayude a actualizarse profesionalmente, su reincorporación al trabajo que tenía como médico al momento de su detención, el registro en el sistema de jubilaciones, además de las correspondientes indemnizaciones a la víctima y sus familiares

75 Caso del Instituto de Reeducación del Menor vs. Paraguay..., cit. Se trata del Instituto de Reeducación del Menor "Panchito López", establecimiento en el que permanecían niños con procesos judiciales. Sin embargo, no contaba con la infraestructura adecuada para un centro de detención de esta naturaleza, lo que provocó que se agravara la situación al superar la población su propia capacidad.

76 Caso Pacheco Teruel y otros vs. Honduras..., cit.

77 Este caso es de particular importancia porque se reitera el estándar sobre condiciones carcelarias y el deber de prevención que el Estado debe garantizar a favor de las 
El mismo criterio es reiterado en la sentencia Cabrera García y Montiel Flores vs. México, pues ambas personas alegaron maltratos y tortura durante el proceso judicial y posteriormente durante el cumplimiento de la condena. Aquí la Corte IDH advirtió que siempre que una persona es detenida en un estado de salud normal y posteriormente aparece con afectaciones a la salud, corresponde al Estado proveer una explicación creíble de dicha situación. ${ }^{78}$ Señaló también que el Estado debe garantizar la independencia del personal médico y de salud encargado de examinar y prestar asistencia a los detenidos de manera que puedan practicar libremente las evaluaciones médicas necesarias, respetando las normas establecidas en la práctica de su profesión. Para ello, en la sentencia dicta reparaciones compensatorias en efectivo por concepto de tratamiento médico y psicológico especializado, así como por medicamentos y otros gastos conexos.

La falta de la debida atención médica brindada a la víctima durante las investigaciones del proceso y el trato especial que debió tener por su condición de niña y perteneciente a un grupo indígena ${ }^{79}$ fue motivo de condena al Estado mexicano en el caso Rosendo Cantú y otra. ${ }^{80}$

Interesa destacar otro caso mexicano en materia de reparaciones: García Cruz y Santiago Sánchez vs. México, ya que la sentencia dictada por la Corte IDH obliga al Estado a otorgar a las víctimas y a familiares atención médica preferencial y gratuita, y brindarles atención psicológica. Así como garantizar la educación de las víctimas hasta la conclusión de sus estudios

personas privadas de su libertad. En específico, la sentencia subraya el hacinamiento; la separación por categorías debe realizarse entre procesados y sentenciados, y entre los menores de edad y los adultos; el acceso al agua potable para consumo, y agua para aseo personal; la alimentación de buena calidad y con valor nutritivo suficiente; la atención médica, tratamiento adecuado y personal médico calificado cuando sea necesario; la educación, trabajo y recreación como funciones esenciales de los centros penitenciarios para promover la rehabilitación y readaptación social de los internos; celdas con suficiente luz natural o artificial, ventilación y condiciones de higiene; servicios sanitarios en condiciones de higiene y privacidad; los Estados no pueden alegar dificultades económicas para justificar detenciones que no cumplan con lo anterior, y que no respeten la dignidad del ser humano, y prohíbe las medidas o sanciones disciplinarias que constituyan un trato cruel, inhumano o degradante, o que pongan en grave peligro la salud física o mental del recluso. Véase párrafo 67 de la sentencia.

78 Caso Cabrera García y Montiel Flores vs. México..., cit., párrafo 134.

79 Párrafos 184, 185 y 201 de la sentencia.

80 Caso Rosendo Cantú y otra vs. México..., cit. 
universitarios o técnicos, según sea su interés y entregar en propiedad una vivienda a cada víctima. ${ }^{81}$

La Corte IDH también tuvo oportunidad de pronunciarse por los derechos de los reclusos y detenidos y la necesidad de que cuenten con asistencia médica en las prisiones tratándose de migrantes, como son los casos Vélez Loor vs. Panamá ${ }^{82}$ y Tibi vs. Ecuador. En el primero, la Corte IDH hace un señalamiento especial del trato y condiciones que los Estados deben garantizar a los detenidos cuando se trate de migrantes. Como lo es el deber de contar con establecimientos especiales y cuidar que las condiciones de la detención sean acordes con la dignidad e integridad personal, para esto, debe garantizarse el suministro de agua necesario para el aseo personal, agua potable y condiciones salubres para atender sus necesidades individuales cotidianas, además de asegurar la asistencia médica que incluya revisión médica regular y tratamiento adecuado. ${ }^{83}$

El caso Tibi vs. Ecuador llevó a la Corte IDH a dictaminar que el Estado incumplió con los Principios para la Protección de todas las Personas sometidas a cualquier Forma de Detención o Prisión de las Naciones Unidas que lo obliga a "ofrecer [...] un examen médico apropiado después de su ingreso en un lugar de detención o prisión" ${ }^{84}$

Igualmente, el caso Vera Vera vs. Ecuador ${ }^{85}$ se pronuncia directamente sobre la atención médica como parte del derecho a la integridad personal

81 Los señores García Cruz y Sánchez Silvestre fueron detenidos y sometidos a tortura para obtener una confesión por los cargos imputados en su contra. Caso García Cruz y Sánchez Silvestre vs. México. Fondo, reparaciones y costas, sentencia de 26 de noviembre de 2013, serie C, núm. 273, ficha técnica disponible en http://www.corteidh.or.cr/cfl Jurisprudencia2/ficha_tecnica.cfm?nId_Ficha=378\&lang=es.

82 Caso Vélez Loor vs. Panamá. Excepciones preliminares, fondo, reparaciones y costas, sentencia de 23 de noviembre de 2010, serie C, núm. 218, ficha técnica disponible en http://www.corteidh.or.cr/docs/casos/articulos/seriec_218_esp2.pdf. El señor Vélez, de nacionalidad ecuatoriana, fue detenido por no contar con la documentación necesaria. La Dirección de Migración y Naturalización de Panamá dictó orden de detención en su contra, y fue trasladado a una cárcel donde recibió condena por dos años de prisión. Posteriormente, la sentencia fue revertida, y el señor Vélez fue deportado a su país, donde inició trámite contra el Estado por tortura y malos tratos ocurridos durante su estancia en los diversos centros penitenciarios de Panamá.

83 Párrafos 215, 216 y 223 de la sentencia.

84 Caso Tibi vs. Ecuador..., cit., párrafos 151-157.

85 Caso Vera Vera y otra vs. Ecuador..., cit. Pedro Vera, al ser detenido por la policía por presunto delito de asalto y robo a mano armada, presentaba una bala en el pecho. Fue trasladado en taxi al cuartel de la policía, y después de ser registrado, lo llevaron al hos- 
de los detenidos y reclusos. ${ }^{86}$ En este sentido, señala que el Estado tiene el deber de constituirse como el garante de la salud de las personas bajo su custodia, de proporcionar a los detenidos revisión médica regular, y atención y tratamiento médicos adecuados cuando así lo requiera. ${ }^{87}$

El mismo criterio se reitera en el caso García Asto y Ramírez Rojas vs. Perú donde la Corte IDH observa que, a pesar de problemas de salud, el señor García Asto no recibió la atención médica adecuada, además de que las condiciones de detención impuestas constituyeron tratos crueles e inhumanos que vulneraron su integridad física, psíquica y moral, tanto de las víctimas como de sus familiares. ${ }^{88}$ En este sentido, es conocida la jurisprudencia de la Corte IDH al proteger a los familiares de las víctimas en cuanto a la vulneración de su integridad física y moral padecidos con motivo de las detenciones de las víctimas, como lo subrayó en el caso Gutiérrez Soler vs. Colombia obligando al Estado a proporcionar tratamiento médico y psicológico a la víctima y a sus familiares. ${ }^{89}$

En 2014, la Corte IDH tuvo oportunidad de pronunciarse nuevamente en un caso de detención ilegal y tortura, así como violencia sexual y un grave deterioro de su salud durante el tiempo que permaneció detenida la víctima. ${ }^{90} \mathrm{La}$ Corte IDH determinó la ausencia de atención médica especializada, adecuada y oportuna, ante el deterioro progresivo de salud evidenciado en los informes médicos practicados en la época. Asimismo, en su análisis de fondo, la Corte IDH observó que ni las declaraciones que se le tomaron a la víctima ni los informes médicos correspondientes a los exámenes que se le practicaron cumplieron con los estándares internacionales aplicables para la recaudación de prueba en casos de tortura y violencia sexual, y en

pital, donde fue dado de alta al día siguiente. Debido a las complicaciones de la herida, nuevamente fue llevado al mismo hospital, pero días después fue llevado a otro hospital, donde falleció al día siguiente.

86 En el párrafo 43 de la sentencia, la Corte IDH afirma: "los derechos a la vida y a la integridad personal se hallan directa e inmediatamente vinculados con la atención a la salud humana".

87 Ibidem, párrafo 41 de la sentencia.

88 Caso García Asto y Ramírez Rojas vs. Perú..., cit. Véanse párrafos 215-218 y 233-235.

89 Caso Gutiérrez Soler vs. Colombia..., cit.

90 Caso Espinoza Gonzáles vs. Perú. Excepciones preliminares, fondo, reparaciones y costas, sentencia de 20 de noviembre de 2014, serie C, núm. 289, disponible en http:// www.corteidh.or.cr/docs/casos/articulos/seriec_289_esp.pdf. 
particular, a la recopilación de declaraciones y la realización de evaluaciones médicas y psicológicas. ${ }^{91}$

Un dato por demás interesante es la afirmación de que los médicos y demás miembros del personal de salud están en la obligación de no participar, ni activa ni pasivamente, en actos que constituyan participación o complicidad en torturas u otros tratos crueles, inhumanos o degradantes, incitación a ello o intento de cometerlos. Con la consecuente obligación de notificar posibles abusos o riesgos previsibles.

Asimismo, confirma la obligación del Estado de garantizar la independencia del personal médico y de salud encargado de examinar y prestar asistencia a los detenidos de manera libre, y realizar las evaluaciones médicas necesarias, con respeto a las normas establecidas en la práctica médica. ${ }^{92} \mathrm{En}$ esta línea, se afirma también el deber de abstenerse de obligar de cualquier forma a los médicos a comprometer su independencia profesional. Asegurar que las condiciones contractuales le otorguen la independencia profesional necesaria y el médico forense tiene igualmente una obligación de imparcialidad y objetividad frente a la evaluación de la persona a quien examina.

En conclusión, en este grupo de sentencias puede observarse que la Corte IDH aplicó el principio de indivisibilidad e interdependencia de los derechos humanos. Por una parte, porque en materia de violación a la libertad personal y detenciones arbitrarias, la Corte IDH tomó en consideración aspectos relativos a la salud, sobre todo en materia de reparaciones, cuando determinó la obligación del Estado de proporcionar atención médica y psicológica a las víctimas y sus familiares por el daño en su salud ocasionado, además de la obligación de proporcionar una educación completa y vivienda.

91 Asimismo, la Corte recordó que en casos de violencia contra la mujer, al tomar conocimiento de los actos alegados, es necesario que se realice inmediatamente un examen médico y psicológico completo y detallado por personal idóneo y capacitado, en lo posible del sexo que la víctima indique, ofreciéndole que sea acompañada por alguien de su confianza si así lo desea. Dicho examen deberá ser realizado de conformidad con protocolos dirigidos específicamente a documentar evidencias en casos de violencia de género. Más aún, la Corte recordó que, en casos de violencia sexual, la investigación debe intentar evitar en lo posible la revictimización o reexperimentación de la profunda experiencia traumática a la presunta víctima.

${ }^{92}$ El deber de independencia exige que el médico tenga plena libertad de actuar en interés del paciente, e implica que los médicos hagan uso de las prácticas médicas óptimas, sean cuales fueren las presiones a las que puedan estar sometidos, incluidas las instrucciones que puedan darle sus empleadores, autoridades penitenciarias o fuerzas de seguridad. 
También es posible advertir esta técnica judicial cuando en los casos que se conculcaron derechos de libertad personal e integridad personal de los detenidos, la Corte tomó en consideración aspectos de índole sanitaria al momento de establecer la responsabilidad del Estado y los medios de reparación aplicables, como el de brindar atención médica regular y tratamiento adecuado a los internos. Lo mismo para las condiciones de vida digna en los centros penitenciarios como el contar con agua, condiciones salubres, alimentación, atención médica y médicos independientes que apliquen los criterios internacionales establecidos en esta materia.

\section{Derecho a la protección de la salud y grupos vulnerables}

En este grupo de sentencias se analizará la jurisprudencia de Corte IDH en casos donde están presentes víctimas que pertenecen a grupos vulnerables de la sociedad, como niños y adolescentes, comunidades y pueblos indígenas, personas con discapacidad, así como migrantes. En estos casos, la Comisión alegó violación al artículo de la CADH referido a las garantías judiciales.

El numeral 8 de la CADH señala lo siguiente:

Toda persona tiene derecho a ser oída, con las debidas garantías y dentro de un plazo razonable, por un juez o tribunal competente, independiente e imparcial, establecido con anterioridad por la ley, en la sustanciación de cualquier acusación penal formulada contra ella, o para la determinación de sus derechos y obligaciones de orden civil, laboral, fiscal o de cualquier otro carácter.

Por otro lado, se consagra el principio de presunción de inocencia y el goce de garantías mínimas dentro del proceso judicial como son:

a) Ser asistido gratuitamente por el traductor o intérprete, si no comprende o no habla el idioma del juzgado o tribunal.

b) Comunicación previa y detallada al inculpado de la acusación formulada.

c) Concesión al inculpado del tiempo y de los medios adecuados para la preparación de su defensa.

d) Derecho del inculpado de defenderse personalmente o de ser asistido por un defensor de su elección y de comunicarse libre y privadamente con su defensor. 
e) Derecho irrenunciable de ser asistido por un defensor proporcionado por el Estado, remunerado o no según la legislación interna, si el inculpado no se defendiere por sí mismo ni nombrare defensor dentro del plazo establecido por la ley.

f) Derecho de la defensa de interrogar a los testigos presentes en el tribunal y de obtener la comparecencia, como testigos o peritos, de otras personas que puedan arrojar luz sobre los hechos.

g) Derecho a no ser obligado a declarar contra sí mismo ni a declararse culpable, y

h) Derecho de recurrir del fallo ante juez o tribunal superior.

También en este grupo de casos se advierte la conexión de derechos de la Corte IDH con otro derecho como el de la protección judicial, el cual se encuentra previsto en el artículo 25 de la $\mathrm{CADH}$, que establece el derecho de toda persona a un recurso sencillo y rápido ante los jueces o tribunales competentes, que la amparen contra actos que violen sus derechos fundamentales reconocidos por la Constitución, la ley o la presente Convención, aun cuando tal violación sea cometida por personas que actúen en ejercicio de sus funciones oficiales.

Para tal efecto, la CADH establece que es obligación de los Estados parte: a) garantizar que la autoridad competente, prevista por el sistema legal del Estado, decidirá sobre los derechos de toda persona que interponga tal recurso; b) desarrollar las posibilidades de recurso judicial, y c) garantizar el cumplimiento, por las autoridades competentes, de toda decisión en que se haya estimado procedente el recurso.

Veamos algunos ejemplos que puedan mostrar lo anterior.

\section{Obligación del Estado de otorgar una protección especial} a los menores de edad, así como tratamiento médico $y$ psicológico a víctimas y familiares

En el caso Instituto de Reeducación del Menor la sentencia hace una condena a los Estados por no haber resuelto las acciones legales de las víctimas o los familiares de los detenidos que fallecieron en el incendio para buscar una indemnización. Por lo que, ante la imposibilidad de reparación en el caso de los fallecidos, la sentencia obliga al Estado a brindar el tratamiento médico y psicológico a los supervivientes heridos así como a sus 
familiares. Además de las condenas compensatorias por daños materiales a las víctimas y sus familiares.

\section{Obligación del Estado por falta de garantías judiciales} que preserven la atención en rehabilitación $y$ en la salud de personas con discapacidad mental u otras, así como a sus familiares

Respecto a los derechos de las personas con discapacidad, el caso Furlan $y$ familiares $v$ s. Argentina ${ }^{93}$ resulta muy atrayente porque se refiere a un niño con discapacidad a consecuencia de un accidente en un predio propiedad del Gobierno. La Corte IDH sostuvo que, al tratarse de una persona con discapacidad y menor de edad, es titular de una protección especial. Por lo que condenó al Estado por haber violentado su derecho a recibir atención médica adecuada, pues al retrasarse el pago de la indemnización que necesitaba no pudo recibirla. Y por no haber otorgado una indemnización completa e integral por evidente irresponsabilidad del Estado durante la tramitación de los juicios llevados a cabo por el padre del menor.

Además, la sentencia condena por la violación al derecho a la integridad personal de los familiares cercanos por verse enfrentados a la incertidumbre e inseguridad por la vulneración de su familia. En suma, el haber denegación del acceso a la justicia tuvo impacto en la posibilidad de acceder a una adecuada rehabilitación y atención en la salud. ${ }^{94}$

En el caso Rosendo Cantú y otra vs. México ${ }^{95}$ de igual forma, la Corte IDH dictaminó que el Estado tiene la obligación de tomar medidas especiales a favor de la entonces menor de edad señora Rosendo Cantú, además por tratarse de una persona indígena. Aquí, nuestro país fue condenado porque la menor de edad no contó, durante el procedimiento judicial penal, con intérprete, tampoco se le brindó atención médica por el abuso sexual sufrido.

93 Caso Furlan y familiares vs. Argentina..., cit. El padre del menor obtuvo como indemnización compensatoria el pago de una suma de dinero, la cual se vio sumamente mermada luego de hacer los pagos que debía por los trámites judiciales y médicos. Durante el procedimiento se dictaminó que requiere asistencia médica especializada de por vida, pues tiene un setenta por ciento de discapacidad. Por lo cual su padre reclama una pensión por invalidez.

94 Caso Furlan y familiares vs. Argentina..., cit., párrafos 214, 222 y 269 de la sentencia.

95 Caso Rosendo Cantú y otra vs. México..., cit., párrafos 184, 185 y 201. 
La Corte deriva estas conductas en infracciones al deber de garantizar un debido acceso a la justicia en los términos que hemos señalado de la $\mathrm{CADH}$.

Cabe señalar un caso de la mayor relevancia para nuestro tema, porque la Corte IDH trata directamente el deber del Estado de vigilar y fiscalizar a las entidades de salud públicas o privadas, así como el deber de cuidado en relación con las personas ahí internadas. Me refiero al asunto Ximénes Lopes vs. Brasil ${ }^{96}$ el cual relata que el demandante desarrolló, durante su juventud, una discapacidad mental, por lo que fue recluido en una Casa de Reposo del sistema de salud pública en perfectas condiciones de salud física.

Sin embargo, al día siguiente de su internamiento sufrió una severa crisis de agresividad y desorientación. Un día después, su madre lo encontró con múltiples heridas en el cuerpo, con la ropa sucia y agonizante. Ese mismo día, falleció después de haber sido medicado por el director del hospital y sin asistencia médica al momento de su muerte.

En este caso, la Corte IDH fundamenta la interpretación del derecho a la integridad personal con el derecho a la salud en instrumentos internacionales en la materia. ${ }^{97}$ Así, determina como deberes del Estado en relación con la protección de la salud: asegurar una prestación médica eficaz a las personas con discapacidad mental. Esto es asegurar el acceso al servicio de salud, la promoción de la salud mental y la prevención de las discapacidades mentales. ${ }^{98}$ Segundo, estos tratamientos deben tener como finalidad el bienestar del paciente y el respeto a su dignidad como ser humano. Por ello, deben adoptar como principios orientadores del tratamiento psiquiátrico el respeto a la intimidad, y la autonomía de las personas. Tercero, la adopción de medidas necesarias para impedir el deterioro de la condición del paciente y optimizar su salud. Cuarto deber, cuidar su máxima exigencia cuando se trata de pacientes con discapacidad mental en instituciones psiquiátricas, sin importar si se trata de instituciones públicas o privadas..$^{99}$ Finalmente, cumplir con los compromisos internacionales para las investigaciones forenses, como sucedió en este caso. Pues la sentencia determinó que hubo

96 Caso Ximenes Lopes vs. Brasil..., cit.

97 Principios para la Protección de los Enfermos Mentales y el Mejoramiento de la Atención de la Salud Mental de las Naciones Unidas; Principios para la Protección de los Enfermos Mentales y el Mejoramiento de la Atención de Salud Mental; Declaración de Madrid sobre los Requisitos Éticos para la Práctica de la Psiquiatría; Normas Uniformes sobre la Igualdad de Oportunidades para las Personas con Discapacidades.

98 Caso Ximenes Lopes vs. Brasil..., cit., párrafo 128 de la sentencia.

99 Ibidem, párrafos 130, 139 y 140 de la sentencia 
una falta de diligencia debida al no iniciar inmediatamente la investigación de los hechos, lo que impidió la oportuna conservación de las pruebas y la identificación de testigos oculares. ${ }^{100}$

\section{Obligación del Estado de respetar el derecho a fundar una familia y no ser discriminado por enfermedad, así como el derecho a la salud sexual y reproductiva}

En 2012, la Corte IDH tuvo en sus manos un caso por demás atractivo, del cual derivó no sólo el derecho a la salud, sino su relación con el derecho a formar una familia, con el derecho a no ser discriminado por enfermedad y con el derecho a gozar de los avances del progreso científico. Reseño el caso Artavia Murillo y otros (fertilización in vitro) vs. Costa Rica. ${ }^{101}$ El juicio se refiere a la responsabilidad internacional del Estado por las afectaciones generadas a un grupo de personas a partir de la prohibición general de practicar en su país la fecundación in vitro (en adelante, FIV). ${ }^{102}$

La sentencia de la Corte IDH presenta el análisis a partir de los derechos a la vida privada y familiar por lo que, al impedir la maternidad — que forma parte esencial del libre desarrollo de la personalidad de las mujeres-, se limita el derecho a la vida privada e incluye, en el presente caso, la obligación del Estado de favorecer todas las posibilidades para el desarrollo de la familia. De conformidad con lo señalado en el artículo 17.1: la familia es el elemento natural y fundamental de la sociedad y debe ser protegida por la sociedad y el Estado

100 Ibidem, párrafos 187-191 de la sentencia.

101 Caso Artavia Murillo y otros (fertilización in vitro) vs. Costa Rica..., cit.

${ }^{102}$ Los demandantes señalaron como fundamento además: el Convenio para la Protección de los Derechos Humanos y la Dignidad del Ser Humano con respecto a la Aplicación de la Biología y la Medicina; el Convenio Europeo para la Protección de los Derechos Humanos y de las Libertades Fundamentales; la Convención para la Eliminación de Todas las Formas de Discriminación contra la Mujer, Convención sobre los Derechos de las Personas con Discapacidad, la Convención de los Derechos del Niño, la Declaración Americana sobre los Derechos y Deberes del Hombre, Declaración de las Naciones Unidas sobre la utilización del Progreso Científico y Tecnológico en Interés de la Paz y en beneficio de la Humanidad y el Protocolo adicional de la Convención Americana sobre Derechos Humanos en Materia de Derechos Económicos, Sociales y Culturales, conocido también como "Protocolo de San Salvador". 
Tratándose, como es el caso, de parejas con infertilidad y su relación con el derecho a la salud, la Corte IDH señaló que el derecho a la vida privada, a la libertad y a la familia se relacionan directamente con: a) la autonomía reproductiva, b) el acceso a servicios de salud reproductiva y c) el derecho de acceder a la tecnología médica necesaria para ejercer ese derecho. Sobre los derechos reproductivos se indicó que éstos se basan en el reconocimiento del derecho de todos los individuos a decidir libre y responsablemente el número de hijos, el espaciamiento de los nacimientos y el intervalo entre éstos, y a disponer de la información y medios necesarios para ello, así como el derecho a alcanzar el nivel más elevado de salud sexual y reproductiva. De esto deriva el derecho a acceder a los mejores servicios de salud en técnicas de asistencia reproductiva y, en consecuencia, la prohibición de restricciones desproporcionadas e innecesarias de iure o de facto para ejercer las decisiones reproductivas.

En consecuencia, la Corte IDH razonó que sí hubo injerencia en la vida personal y familiar de estas personas, ya que se generó la interrupción del procedimiento en el caso de las parejas que lo habían iniciado, y otras tuvieron que viajar a otro país para continuarlo. Incluso, la injerencia se circunscribe a la posibilidad de tomar una decisión autónoma sobre el tipo de tratamientos que querían intentar para ejercer sus derechos sexuales y reproductivos.

En efecto, resulta esclarecedor que la Corte IDH tome nota de que la infertilidad es "una enfermedad del sistema reproductivo definida como la incapacidad de lograr un embarazo clínico después de 12 meses o más de relaciones sexuales no protegidas". Por lo tanto, consideró que la infertilidad es una limitación funcional reconocida como una enfermedad y que las personas con infertilidad en Costa Rica, al enfrentar las barreras generadas por la decisión de la Sala Constitucional, debían considerarse protegidas por los derechos de las personas con discapacidad, que incluyen el derecho de acceder a las técnicas necesarias para resolver problemas de salud reproductiva.

Finalmente, la Corte IDH concluye afirmando que la afectación del derecho a la integridad personal, libertad personal, vida privada, la intimidad, la autonomía reproductiva, el acceso a servicios de salud reproductiva y a fundar una familia es severa y supone una violación de dichos derechos, pues éstos son anulados en la práctica para aquellas personas cuyo único tratamiento posible de la infertilidad era la FIV. Asimismo, la interferencia 
tuvo un impacto diferenciado en las víctimas por su situación de discapacidad, los estereotipos de género y, frente a algunas de las presuntas víctimas, por su situación económica.

Este caso es paradigmático porque la Corte IDH refiere al artículo 14 del Protocolo de San Salvador, el cual en el apartado 1.b establece la obligación de los Estados partes a reconocer el derecho de toda persona a gozar de los beneficios del progreso científico y tecnológico. Con lo cual, la técnica de FIV constituye por el momento, la mejor opción para que estas parejas desarrollen su derecho a la vida privada y a la formación de una familia.

Se analiza ahora un grupo de casos contenciosos en los que se dictaron sentencias que en los últimos diez años hacen referencia al derecho a la salud en la protección que hizo la Corte IDH de otros derechos de comunidades y grupos indígenas como el derecho a la vida, la identidad cultural y el derecho a la propiedad privada.

Como hemos visto, en los casos Comunidad Yakye Axa y Comunidad Indígena Xákmok Kásek, ambos contra el Estado de Paraguay, la Corte IDH interpretó, de acuerdo al artículo 4 de la $\mathrm{CADH}$, el derecho a la vida como la obligación del Estado de generar las condiciones mínimas de existencia, o bien no producir condiciones que la dificulten o impidan. Para ello discurre que las afectaciones a la salud, las del derecho a la alimentación y el acceso al agua limpia impactan de manera aguda el derecho a una existencia digna. ${ }^{103}$

En el caso Comunidad Indígena Sawhoyamaxa vs. Paraguay derivó la violación al derecho a la vida porque el Estado permitió la carencia de sus tierras y no suministró las condiciones necesarias para que los enfermos de la comunidad, los ancianos, mujeres embarazadas y niños tuvieran acceso a un centro médico o de salud. ${ }^{104}$ En el caso del Pueblo Indígena Kichwa de Sarayaku vs. Ecuador señaló que el derecho a la consulta de las comunidades indígenas y tribales está cimentado en el derecho a la identidad cultural, por lo cual, impone al Estado de realizar dicha consulta y los estudios de impacto ambiental que los proyectos de desarrollo e infraestructura se realicen en sus territorios o tierras tribales. ${ }^{105}$

103 Caso comunidad indígena Yakye Axa vs. Paraguay..., cit., párrafo 167 de la sentencia; caso comunidad indígena Xákmok Kásek vs. Paraguay. Fondos, reparaciones y costas, sentencia del 24 de agosto de 2010, párrafo 208.

104 Caso comunidad indigena Sawhoyamaxa vs. Paraguay..., cit., párrafos 168, 174, 176, 177 y 178.

105 Caso del pueblo indigena Kichwa de Sarayaku vs. Ecuador..., cit., párrafos 159, $167,187,204$ y 205 de la sentencia. 


\section{Respeto al derecho a la salud, en caso de las personas migrantes} detenidas, mediante el otorgamiento de servicios de salud accesibles, especialmente menores y mujeres embarazadas

Es importante mencionar algunos casos en los cuales la Corte IDH precisa la obligación de brindar servicios de salud a los migrantes, en especial a los sectores más vulnerables y marginados como menores de edad o mujeres embarazadas. ${ }^{106}$

En $2013^{107}$ la Corte IDH derivó el derecho de cualquier persona extranjera, y no solamente a los asilados o refugiados, a la no devolución indebida cuando su vida, integridad y/o libertad estén en riesgo de violación, sin importar su estatuto legal o condición migratoria en el país en que se encuentra. Por lo que la Corte aludió al derecho a la integridad psíquica y moral al considerar la zozobra, el temor y la desprotección provocada por los hechos violentos y de peligro. Cabe mencionar que la Corte IDH refiere los derechos de los niños, pues deben gozar de procedimientos apropiados y seguros, y de un ambiente que le genere confianza en todas las etapas del proceso de asilo.

La Corte IDH reiteró estos principios al año siguiente en razón del caso Personas Haitianas y Dominicanas Expulsadas vs. República Dominicana, ${ }^{108}$ pues las víctimas fueron detenidas de manera arbitraria e ilegal, y que durante su detención no recibieron agua, alimentos ni asistencia médica, así como que permanecieron incomunicadas y no pudieron contactarse con sus familiares para informarles de su detención y expulsión. Lo anterior afectó la integridad psíquica de los migrantes. Lo que produjo en las víctimas sufrimientos mentales o psicológicos injustificables. Dada su especial situación de vulnerabilidad, el Estado estaba en la obligación de adoptar medidas especiales de protección a su favor, tal y como lo prevé el artículo 19 de la $\mathrm{CADH},{ }^{109}$ y como lo estableció en el caso Vélez Loor vs. Panamá sobre los derechos de asistencia médica de los migrantes detenidos. ${ }^{110}$

106 Caso Nadege Dorzema y otros vs. República Dominicana..., cit., párrafos 104, 107, 108 y 109.

107 Véase caso familia Pacheco Tineo vs. Bolivia..., cit.

108 Véase caso personas dominicanas y haitianas expulsadas vs. República Dominicana..., cit.

109 Ibidem, párrafos 424 y 438 de la sentencia.

110 Véase caso Vélez Loor vs. Panamá..., cit., párrafos 198 y 204 de la sentencia. 
En conclusión, de este breve repaso es posible advertir que la Comisión presentó estos casos con el fin de que la Corte IDH decidiera si los Estados vulneraron derechos consagrados en los artículos 1 (Obligación de respetar los derechos), 2 (Deber de adoptar disposiciones de derecho interno), 21 (Derecho a la propiedad privada) y 25 (Protección judicial), principalmente.

En las sentencias, la Corte IDH aplicó nuevamente la técnica de conexión de derechos, ya que estimó vulnerados los derechos de propiedad, el derecho a la vida familiar y libertad personal, para tomar en consideración la afectación de otros derechos de las personas que supusieron incumplimiento por parte del Estado, como en el caso de la vigilancia y fiscalización de las clínicas y hospitales de salud mental, la atención médica en los centros penitenciarios de menores y la falta de garantías judiciales pusieron en peligro las condiciones de vida digna de las comunidades indígenas, tales como el acceso a agua potable, centros de salud, alimentación suficiente y adecuada.

Cabe destacar aquí que la Corte IDH aludió directamente a la aplicación del Protocolo de San Salvador, al señalar el derecho a gozar de los beneficios de la cultura, entre ellos, los beneficios del progreso científico y tecnológico, como un deber de los Estados de respetar.

En otras palabras, la Corte IDH tomó en consideración aspectos socioeconómicos y culturales al momento de establecer la responsabilidad del Estado, y también al momento de las reparaciones.

\section{DERECHO A LA SALUd, A LOS BENEFICIOS DE LA CIENCIA Y EL PROGRESO CIENTÍFICO, Y LA NORMATIVIDAD \\ DE LA PRÁCTICA MÉDICA}

En este apartado examinaré la interpretación de la Corte IDH tratándose de casos que involucraron decisiones del Estado que derivaron en una mala práctica médica y asuntos de política sanitaria que limitaron el acceso al derecho a la ciencia y el progreso.

\section{Responsabilidad del Estado por mala práctica médica}

y no observar los protocolos internacionales en la materia médica y de asistencia sanitaria

Por un lado, resulta relevante para esta temática el caso Albán Cornejo que ya he comentado. ${ }^{111}$ Interesa resaltar que la Corte IDH con fundamento

111 Véase el caso Albán Cornejo y otros vs. Ecuador..., cit. En este asunto, el quejoso 
en el Protocolo de San Salvador señala que toda persona tiene derecho a la salud, entendida como el disfrute del más alto bienestar físico, mental y social, e indica que la salud es un bien público. ${ }^{112}$ Por lo anterior, el Estado es responsable por la omisión de cumplimiento de supervisar la prestación del servicio para proteger dicho bien público. ${ }^{113}$ Sobre todo, que consideró violentado su deber de contar con una normatividad eficaz para garantizar a los usuarios del servicio de salud una efectiva investigación de las conductas que vulneren sus derechos, especialmente, normas sobre mala praxis médica. ${ }^{114} \mathrm{Y}$, finalmente, remite a la observancia de instrumentos internacionales, ${ }^{115}$ que determinan los deberes específicos de los médicos y el marco para el desempeño de la profesión sujeta a los principios éticos y jurídicos de relevancia para el caso.

Este mismo criterio lo aplicó en 2005 en el caso Ximenes López vs. Brasil que ya se comentó anteriormente, que refiere a la muerte de un interno en una clínica para personas con discapacidad mental. Como se vio, la Corte IDH estimó que el Estado es el garante de las personas bajo su custodia, y con mayor razón tratándose de grupos de personas en una especial situación de vulnerabilidad, como lo son las personas que padecen una enfermedad mental, ya sea una entidad pública o privada. ${ }^{116}$

Pues la Corte repitió este criterio en el caso Suárez Peralta vs. Ecua$d o r^{117}$ al constatar la responsabilidad de las autoridades judiciales por las falencias y la demora en el proceso, quienes debieron garantizar a la víctima

acudió a un hospital por un cuadro de meningitis bacteriana, y murió a causa de una prescripción médica de morfina.

112 Ibidem, párrafo 117 de la sentencia

113 Ibidem, párrafos 119 y 121 de la sentencia. La Corte IDH ha manifestado que los Estados son responsables de regular y fiscalizar la prestación de servicios de salud para lograr una efectiva protección de los derechos a la vida e integridad personal.

114 Ibidem, párrafos 123, 124 y 132.

115 Se citan en la sentencia instrumentos internacionales como: Código Internacional de Ética Médica de la Asociación Médica Mundial, Deberes de los Médicos hacia los Pacientes; Principios de Ética Médica de la Asociación Médica Americana; Declaración de Helsinki de la Asociación Médica Mundial; Principios Éticos para las Investigaciones Médicas en Seres Humanos; Principios de Ética Medica aplicables a la Función del Personal de Salud de las Naciones Unidas; Declaración de Tokio de la Asociación Médica Mundial; Normas Directivas para Médicos respecto a la Tortura y Otros Tratos o Castigos Crueles, Inhumanos o Degradantes, Impuestos a las Personas Detenidas o Encarceladas.

116 Véase el caso Ximenes Lopes vs. Brasil..., cit., párrafo 138 de la sentencia.

117 Caso Suárez Peralta vs. Ecuador..., cit. 
una reparación con la que podría acceder al tratamiento médico necesario para su problema de salud.

Interesa insistir que, en este caso, la Corte señaló que a los efectos de dar cumplimiento a la obligación de garantizar el derecho a la integridad personal, los Estados deben establecer un marco normativo adecuado que regule la prestación de servicios de salud, estableciendo estándares de calidad para las instituciones públicas y privadas. Asimismo, se deben prever mecanismos de supervisión y fiscalización estatal de las instituciones de salud, así como procedimientos de tutela administrativa y judicial para el damnificado.

Específicamente, la sentencia señala que se generó una situación de riesgo, porque se demostró que se prestó atención médica en un centro de salud público por parte de quien no acreditó estar certificado para el ejercicio de su profesión, y que, frente a ello, el Estado no sólo permitió sino que además promovió la misma. Señala que este servicio debe asegurar los principios de disponibilidad, accesibilidad, aceptabilidad y calidad de las prestaciones médicas. ${ }^{118}$

\section{Derecho de disfrutar los beneficios del progreso cientifico y la ciencia en materia de salud}

Finalmente regresamos al caso Artavia Murillo y otros ${ }^{119}$ para referirnos al derecho a gozar de los beneficios de la cultura, del progreso científico y la ciencia. En este asunto, la Corte IDH marca una pauta por demás interesante al relacionar este derecho con el derecho a la salud.

Al considerar que la infertilidad es una limitación funcional reconocida como una enfermedad, y que las personas con infertilidad en Costa Rica, al enfrentar las barreras generadas por la decisión de la Sala Constitucional, debían considerarse protegidas por los derechos de las personas con discapacidad, que incluyen el derecho de acceder a las técnicas necesarias para resolver problemas de salud reproductiva.

El derecho a la vida y a la libertad reproductiva guarda relación directa con el derecho a acceder a la tecnología médica necesaria para ejercer ese

118 Respecto de la calidad del servicio, el Estado posee el deber de regular, supervisar y fiscalizar las prestaciones de salud, asegurando, entre otros aspectos, que las condiciones sanitarias y el personal sean adecuados, que estén debidamente calificados, y se mantengan aptos para ejercer su profesión.

119 Caso Artavia Murillo y otros (fertilización in vitro) vs. Costa Rica..., cit. 
derecho, según se desprende del artículo XIII de la Declaración Americana y del artículo 14.1 del Protocolo de San Salvador. Esto es, el derecho de acceso al más alto y efectivo progreso científico, y beneficiarse de él. Del derecho de acceso a este progreso científico para el ejercicio de la autonomía reproductiva y la posibilidad de formar una familia se deriva el derecho a acceder a los mejores servicios de salud en técnicas de asistencia reproductivas; por lo tanto, el Estado no debió imponer restricciones desproporcionadas e innecesarias para ejercer las decisiones reproductivas que corresponden a cada persona. ${ }^{120}$

\section{CONSIDERACIONES PARA EL SISTEMA MEXICANO DE DERECHOS HUMANOS}

En virtud del análisis realizado a las sentencias de la Corte IDH, es posible advertir el panorama constitucional mexicano y su posible impacto en cuanto al alcance y protección del derecho a la salud. Para realizar este propósito, sugiero hacerlo a través de algunas sentencias que son antecedentes de esta nueva forma de entender la constitucionalidad de los derechos en México, y otras posteriores a 2011 que reflejan este entendimiento.

Cabe precisar una cuestión que no por obvia debe ser pasada por alto. En México, el derecho a la salud se encuentra regulado constitucionalmente en el artículo 4 desde 1983 en los siguientes términos:

Toda persona tiene derecho a la protección de la salud. La Ley definirá las bases y modalidades para el acceso a los servicios de salud y establecerá la concurrencia de la Federación y las entidades federativas en materia de salubridad general, conforme a lo que dispone la fracción XVI del artículo 73 de esta Constitución.

En este sentido, el derecho a la salud ha sido considerado directamente justiciable por los tribunales mexicanos, tal como lo ha señalado la jurisprudencia de la Suprema Corte de Justicia. En efecto, el pleno del máximo tribunal en México cambió el tradicional enfoque de los derechos sociales como la educación y la salud, que habían sido entendidos como declaraciones e intenciones "cuya efectiva consecución estaba subordinada a las actuaciones legislativas y administraciones específicas", para sostener que

120 Ibidem, párrafo 150 de la sentencia. 
el juez constitucional "puede contrastar su labor con los estándares contenidos en la propia Ley suprema y en los tratados de derechos humanos que forman parte de la normativa y vinculan a todas las autoridades estatales". ${ }^{121}$ Y otra tesis en la que sostuvo como obligación del Estado "la realización progresiva del derecho a la salud" lo más expedita y eficazmente posible hacia su plena realización. ${ }^{122}$

Interesa por tanto comentar el impacto que las sentencias de la Corte IDH tendrán en los tribunales judiciales en México respecto a la precisión del alcance y contenido del derecho a la salud. Para este propósito, el esquema que propongo, a fin de continuar con la línea de derechos estudiados en la Corte IDH, es la temática de derechos civiles y políticos que se relacionaron con el derecho a la salud.

En primer lugar, conviene señalar que una de las decisiones que define un estándar o guía para la interpretación del derecho a la salud lo constituye la sentencia ${ }^{123}$ que hace referencia a varios instrumentos internacionales en materia de derechos humanos de los que deriva, dice la tesis, que "toda persona tiene derecho a la salud, entendida como el disfrute del más alto nivel de bienestar físico, mental y social". En congruencia con lo anterior, colige la Primera Sala que: "el derecho a la salud debe entenderse como una garantía fundamental e indispensable para el ejercicio de los demás derechos humanos y no sólo como el derecho a estar sano".

Así, el derecho a la salud entraña libertades y derechos, entre las primeras, la relativa a controlar la salud y el cuerpo, con inclusión de la libertad sexual y genésica, y el derecho a no padecer injerencias, torturas, tratamientos o experimentos médicos no consensuales; y entre los derechos, el relativo a un sistema de protección de la salud que brinde a las personas oportunidades iguales para disfrutar del más alto nivel posible de salud. ${ }^{124}$

121 Tesis P.XV/2011, Semanario Judicial de la Federación y su Gaceta, novena época, t. XXXIV, agosto de 2011, p. 31. Registro IUS 161331, Amparo en revisión 315/2010, Jorge Francisco Balderas Woolrich, 28 de marzo de 2011.

122 Tesis P.XVI/2011, Semanario Judicial de la Federación y su Gaceta, novena época, t. XXXIV, agosto de 2011, p. 29. Registro 161333, Amparo en revisión 315/2010, Jorge Francisco Balderas Woolrich, 28 de marzo de 2011.

123 Registro IUS 169316, Amparo en revisión 173/2008, 30 de abril de 2008. Tesis publicada en el Semanario Judicial de la Federación y su Gaceta, novena época, t. XXVIII, julio de 2008, p. 457.

124 Idem. Las cursivas son propias. 
Interesante resulta también la decisión del pleno del Tribunal constitucional que derivó el concepto "el estado integral de bienestar". Sin duda, esto es significativo porque señala límites más amplios de los hasta ahora fijados. De ahí que el goce del derecho se traduce en "obtener un determinado bienestar general integrado por el estado físico, mental, emocional y social de la persona, del que deriva un derecho fundamental más, consistente en el derecho a la integridad físico-psicológica". ${ }^{125}$

Esta interpretación marcó la pauta para resolver otros casos, por ejemplo, tratándose de la reasignación del sexo de una persona transexual se extiende el disfrute y goce del derecho a la protección de la salud en la necesidad de expedirle nuevos documentos de identidad para lograr el estado de bienestar general que implica el disfrute de la garantía en cuestión. ${ }^{126}$

Como puede apreciarse en este aspecto, los tribunales mexicanos, particularmente la Suprema Corte de Justicia de la Nación (SCJN) sigue la definición sobre salud adoptada por instancias internacionales, como la Organización Mundial de la Salud y la misma Corte IDH.

Por otra parte, existen otras sentencias que suponen una interpretación al derecho a la salud desde diferentes aspectos, como por ejemplo, la libertad de trabajo o de comercio. Esto lo vemos en los casos que trataron derechos del consumidor, ${ }^{127}$ la necesidad de que los profesionales de la salud, en este caso los médicos, cuenten con una autorización para realizar cirugías estéticas. ${ }^{128}$

Durante 2012, la Suprema Corte señaló el derecho que tiene una persona afectada de su salud a ser indemnizada a raíz de un accidente, que compense el daño sufrido. ${ }^{129} \mathrm{Y}$ en el mismo sentido, la Segunda Sala de la SCJN obligó al Instituto del Seguro Social a indemnizar por daño moral a una paciente por negligencia médica al no habérsele realizado oportunamente

125 Tesis P.LXXX/2001, Semanario Judicial de la Federación y su Gaceta, novena época, t. XXX, diciembre de 2009, p. 6. Registro 165826, Amparo en revisión 6/2008, 6 de enero de 2009.

126 Idem.

127 Semanario Judicial de la Federación y su Gaceta, novena época, t. XXIX, febrero de 2009, p. 1850. Registro 167938.

128 Jurisprudencia publicada en el Semanario Judicial de la Federación y su Gaceta, novena época, t. XXIX, abril de 2009, p. 510. Registro 169270.

129 Tesis 1a. CXCVI/2012, Semanario Judicial de la Federación y su Gaceta, t. I, septiembre de 2012. Registro 2001745, Amparo directo en revisión 1068/2011, 19 de octubre de 2011 . 
el diagnóstico de la enfermedad que padece, lo que provocó la pérdida de uno de sus órganos. ${ }^{130}$

En este sentido, puede observarse un criterio similar al empleado por la Corte IDH, al determinar la vulneración al derecho a la salud por la falta de garantías judiciales de autoridades u órganos judiciales o administrativos. Sin embargo, destacan las sentencias de la Corte IDH en materia de reparaciones, pues incluyen reparaciones en materia de salud no sólo para las víctimas sino también a los familiares que sufrieron la vulneración de los derechos.

En este sentido, considero oportuno señalar el amplio espectro de protección que otorga el sistema interamericano en las sentencias que refieren a la vida digna, pues no solamente aluden a prestaciones y asistencia médica y sus tratamientos sino que incluyen otros derechos sociales como la educación, vivienda, alimentación, agua potable, condiciones salubres, entre otros. Este criterio fue señalado en septiembre de 2015 en la sentencia Gonzales Lluy y otros vs. Ecuador, que se ha comentado anteriormente.

Respecto a la protección de los derechos de los grupos vulnerables. Se destacan algunas sentencias de los tribunales mexicanos donde se advierte esta tendencia, al igual que en la Corte IDH. Por ejemplo, se ratificó la suspensión de mensajes publicitarios en materia de salud en favor de la salud de un grupo vulnerable como son los niños y los jóvenes. ${ }^{131} \mathrm{Y}$ en otra tesis explicitó que el derecho a la salud impone deberes tanto a los poderes públicos como también a los particulares como una meta inherente al Estado mexicano. ${ }^{132}$

Recientemente destacan criterios en temas relacionados con el interés superior del menor y la prueba pericial genética, ya que, deben conocerse los orígenes biológicos del menor, no sólo para obtener su identidad sino porque incide en la protección de su salud en la vertiente de "prevención y tratamiento de enfermedades, fundamentales para su desarrollo pleno". ${ }^{133}$

130 Amparo directo 70/2014, Suprema Corte de Justicia de la Nación.

131 Tesis 1a. CCI/2012, Semanario Judicial de la Federación y su Gaceta, t. I, septiembre de 2012. Registro 2001684, Amparo en revisión 314/2012. British American Tobacco México, S. A de C. V., 4 de julio de 2012.

132 Tesis 1a. XXIII/2013, Semanario Judicial de la Federación y su Gaceta, décima época, t. I, enero de 2013, p. 626. Registro 2002501, Amparo en revisión 117/2012, Agustín Pérez García y otros, 28 de noviembre de 2012.

133 Tesis XII.2o.1C, Semanario Judicial de la Federación y su Gaceta, décima época. Amparo en revisión 186/2013, 18 de octubre de 2013. 
En 2015 la Segunda Sala de la Suprema Corte sostuvo el criterio que obliga a los hospitales a contar con un espacio especial para los enfermos de VIH. Por ese motivo ordenó a la autoridad adoptar las medidas necesarias para garantizarles el acceso a servicios de salud, al nivel más alto, considerando que por la enfermedad que padecen, deben recibir tratamiento médico en instalaciones separadas del resto de los pacientes, con el propósito de evitar el contagio de otra enfermedad. ${ }^{134}$

Sobre este punto, conviene señalar que la Corte IDH ha señalado que el cumplimiento de las obligaciones del Estado para conseguir el más alto nivel de salud de la persona tiene que ver con el deber de proteger la vida y evitar omisiones que la pongan en peligro. En este sentido, tiene una doctrina sólida sobre el deber de vigilancia y fiscalización de hospitales y clínicas públicas o privadas, con el objetivo de proteger el derecho a la vida.

También debe destacarse el criterio vertido sobre el derecho a gozar de los beneficios del progreso científico. Este derecho no previsto en la Constitución mexicana, puede servir de referente para su puesta en marcha a fin de conseguir el más alto nivel posible de salud. La sentencia dictada en el caso Artavia Murillo y otros vs. Costa Rica es un ejemplo de la interpretación y aplicación de este derecho con sus implicaciones en la salud y la libertad personal.

En síntesis, es posible advertir que la amplia gama de casos sometidos a la jurisdicción de la Corte IDH pueden ser considerados como referentes en las áreas en las que los tribunales mexicanos aún no se ha pronunciado. De hecho, estas sentencias son vinculantes para el Estado mexicano, sea o no parte en dicho caso. Por lo tanto, la conveniencia de conocerlas y analizarlas queda evidente para lograr una protección más amplia de este derecho en el ámbito nacional.

\section{COMENTARIOS FINALES}

La protección del derecho a la salud supone una medida significativa y sensible para la población, ya que los operadores jurídicos del país, principalmente las autoridades, deberán proteger la salud en todos los aspectos a

134 "Segunda Sala ampara a enfermos de VIH-SIDA para que reciban atención médica especializada", Canal Judicial, 18 de diciembre de 2014, disponible en https://mail.goo gle.com/mail/u/0/?pli=1\#search/canal+judicial/14a5ec5f055c6aaa. 
los que se refieran los tratados internacionales que México haya suscrito. El impacto que esto tendrá en la protección del derecho a la salud adquiere nuevas dimensiones que suponen un debate por demás interesante en cuanto al ámbito de protección al derecho a la salud.

De esto resulta relevante señalar la necesidad de robustecer el diálogo judicial entre las instancias nacionales e internacionales, especialmente, en la recepción de la jurisprudencia emanada de las decisiones de la Corte IDH.

Para lograr esta finalidad, en estas líneas se han planteado contextos en los que pueden construirse nuevas formas de entendimiento de este derecho que pueden impactar favorablemente en la protección del derecho a la salud en el ámbito nacional.

Por un lado, gracias a la doctrina jurisprudencial que la Corte IDH ha establecido históricamente, es posible verificar que la relación entre los derechos civiles y políticos, como los aquí descritos, resulta comparativamente en una protección mayor a la realizada en el entorno nacional. Esto se considera así por varias razones. Primera, los criterios de interpretación sobre los alcances del derecho a la salud a partir de otros derechos, como el derecho a la vida, a la integridad personal y a las garantías judiciales, que la Corte IDH ha elaborado, permiten visualizar un alcance mayor de protección que en el ámbito nacional, como son los casos de las personas detenidas, internos en las cárceles, situaciones de tortura y tratos crueles e inhumanos, así como la protección a grupos en situación de vulnerabilidad como los migrantes, grupos y comunidades indígenas y los menores.

En segundo término, la línea jurisprudencial aquí expuesta nos orienta sobre la relación de este derecho a la salud vinculado a la realización de otros derechos sociales, como el agua, la alimentación, la vivienda o la educación.

En tercer lugar, los casos aquí analizados nos enseñan que la acción de justicia de los derechos sociales - como el derecho a la salud — está vinculada con el ejercicio de los derechos de los grupos en situación de vulnerabilidad en la sociedad o históricamente en situación de discriminación, como los enfermos de VIH/SIDA, enfermedades raras, acceso a medicamentos caros, y en general, asistencia sanitaria, que suponen cuotas de protección más amplias que las realizadas en el nivel interno.

No es de olvidar el surgimiento de litigios de otros derechos previstos en el Protocolo de San Salvador, que no han sido tratados en el caso mexicano, como es el caso del derecho a gozar de los beneficios de la ciencia y del progreso científico para conseguir el más alto nivel de bienestar. La 
aceptación y progresiva utilización de estos criterios por parte de los jueces y litigantes equivale a colocarse en el camino de un progreso importante en la lucha por la protección de los derechos humanos.

En suma, la idea vertida aquí que plantea la posibilidad de que la Corte IDH conozca directamente de litigios en materia de salud a través de la interpretación del artículo 26 de la $\mathrm{CADH}$, en cuanto a la exigibilidad de progresividad de los derechos económicos, sociales y culturales, parece que pueda abrir niveles de protección más amplios, y contenidos más específicos para el desarrollo del derecho a la salud.

Sin duda, el debate en torno al litigio en materia del derecho a la salud viene acompañado por las fuerzas que lo impulsan como se ha visto y, por otro lado, es evidente el impacto que ejerce esta idea sobre las políticas públicas y el presupuesto.

Fecha de recepción: 18 de agosto de 2015.

Fecha de dictamen: 20 de septiembre de 2015. 